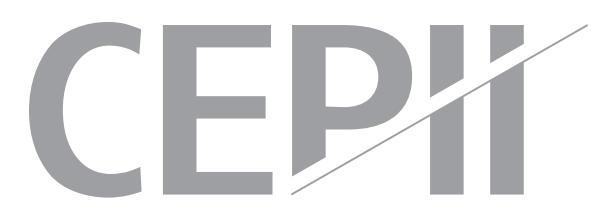

\title{
Immigrants and Firms' productivity: Evidence from France
}

Cristina Mitaritonna , Gianluca Orefice \& Giovanni Peri

\section{Highlights}

- Supply-driven increase in foreign born workers in a department (location) increases the productivity of firms in that department. The previous effect is significantly stronger for firms with initially low (or zero) level of foreign employment.

- Productivity effect of immigrants is associated with faster growth of capital and improved export performances (both extensive and intensive margins) of the firms.

- Supply-driven increase in foreign born workers in a department (location) implies a re-allocation of native workers towards communication and cognitive intensive tasks. 


\section{Abstract}

Immigrants may complement native workers, allow reallocation by skill in the firm and lower costs. These effects could be beneficial for the firm and increase its productivity and profits. However not all firmes use immigrants. Allowing firms to have differential fixed cost in hiring immigrants, because of different information and access to their network, we analyze the impact of an increase in local supply of immigrants on firms' immigrant employment and productivity. Using micro-level data on French firms during the period 1995-2005, we show that a supply-driven increase in foreign born workers in a department (location) increases the productivity of firms in that department. We also find that this effect is significantly stronger for firms with initially low (or zero) level of foreign employment. Those are also the firms whose share of immigrants increases the most. We also find that the positive productivity effect of immigrants is associated with faster growth of capital and improved export performances (for extensive and intensive margin) of the firms. While these outcomes depend on the firm share of immigrants in employment we find a positive effect of immigration on wages of natives and on specialization of natives in complex occupations that is common to all firms in the district. Supply-driven increase in foreign born workers in a department (location) implies a re-allocation of native workers towards communication and cognitive intensive tasks.

\section{Keywords}

Immigrants; Firms; Productivity; Heterogeneity; Fixed Cost of hiring.

I JEL

F22, E25, J61.

\section{Working Paper}

\section{CEPI}

CEPII (Centre d'Etudes Prospectives et d'Informations Internationales) is a French institute dedicated to producing independent, policyoriented economic research helpful to understand the international economic environment and challenges in the areas of trade policy, competitiveness, macroeconomics, international finance and growth.
CEPII Working Paper

Contributing to research in international economics

C C CEPII, PARIS, 2014

All rights reserved. Opinions expressed in this publication are those of the author(s) alone.

$\begin{array}{ll}\text { Editorial Director: } & \text { CEPII } \\ \text { Sébastien Jean } & 113, \text { rue de Grenelle } \\ & 75007 \text { Paris } \\ \text { Production: } & +33153685500 \\ \text { Laure Boivin } & \\ \text { No ISSN: } 1293-2574 & \text { Prw.cepii.fr }\end{array}$




\title{
Immigrants and Firms'productivity: Evidence from France ${ }^{1}$
}

\author{
Cristina MitaritonnaCEPII, 113 rue de Grenelle - 75007 Paris (France), \\ (cristina.mitaritonna@cepii.fr)
}

Gianluca Orefice CEPII, 113 rue de Grenelle - 75007 Paris (France),

(gianluca.orefice@cepii.fr)

Giovanni Peri University of California, Davis. Department of Economics UC Davis, One shield Avenue, Davis CA 95616, (gperi@ucdavis.edu)

\section{Introduction}

In many industrialized countries, among the supporters of more open immigration policies towards economic migrants one usually finds entrepreneurs and employers. ${ }^{2}$ Some people say that this is because immigration helps them to keep wage of workers low. Other people emphasize that it is because immigrants supply skills complementary to those of natives and allow for efficient specialization, and higher firm productivity. The present paper, using French data, analyzes which of these two explanations is supported by the data by analyzing the effect of immigration on firms' productivity and wages. Some recent papers have found indirect evidence that local availability of immigrants may benefit productivity and increase the surplus of local firms. Their specialization of immigrants in manual production tasks complementary

\footnotetext{
${ }^{1}$ We are grateful to participants of CEPII internal seminar 2012 and CEPII-PSE workshop 2013. We thank Matthieu Crozet, Lionel Fontagné and Thierry Mayer for helpful comments. This work benefited from a State aid managed by the National Agency for Research, through the program "Investissements d'avenir", with the following reference: ANR-10-EQPX-17 (Remote Access to data - CASD). Customs data and DADS database were acceded at CEPII. The usual disclaimers apply. The views expressed are purely those of the authors and may not under any circumstances be regarded as stating an official position of the institutions they are affiliated to.

${ }^{2}$ In March 2013 tech industry groups (such as IT Industry Council, the Silicon Valley Leadership, and others) in a letter addressed to President Obama (full text here: http://fr.scribd.com/doc/130388692/Tech-CEOletter) pushed for immigration reforms allowing the entry of more high-skilled immigrants ( $\mathrm{H} 1-\mathrm{B}$ visa). As an example, in 2013, in less than one week companies petitioned for $124000 \mathrm{H} 1-\mathrm{B}$ visa with only 84000 available. But also companies operating in different sectors push for reforms on immigration (construction, maintenance sector, food and other).
} 
to those performed by natives (Peri and Sparber 2009), their lower cost per unit of output (Ottaviano, Peri and Wright 2013), their lower bargaining power (Chassamboulli and Palivos, 2013) and the potential stimulus to investment and technological adoption (Lewis, 2013) may contribute to increase the productivity and/or surplus of firms when hiring immigrants. There is however scant direct empirical evidence on the impact of immigrants on firms' productivity (surplus) due to limited data availability. Moreover even in regions where immigrant supply is large not all firms hire them. In particular some firms may have a significant fixed cost of hiring them, because of lack of knowledge, limited access to their networks or high costs of screening them. In trying to identify the impact of immigrants on productivity of the firm we need to allow for potential heterogeneity of costs of hiring them.

Our approach in this paper is to use "area" variation in the availability of immigrants, due to supply-driven changes of immigrants across French "Departments" (Geographical Districts) over time due to supply shock. We consider the differential response of firms in hiring them as driven by differential fixed cost of hiring them, controlling for and interacting with initial immigrant-share across firms. Within this framework a simple model delivers the prediction that firms that are heterogeneous in the cost of hiring immigrants will respond differently to the common increase in supply and the productivity consequences will be different across them. Specifically, the availability of data on employment by nativity, capital, output, productivity and other characteristics for the universe of French manufacturing firms in the period 1995-2005, allows us to identify firms in regional labor markets ("departments"), that experienced large or small variation in immigrants over the considered period. Then, using an instrumental variable method, we analyze the response of firm-level productivity to supplydriven changes of immigrants, distinguishing between firms with higher fixed costs of hiring them (revealed by a zero initial share of immigrants among workers) and firms with lower fixed costs (with a non-zero initial share of immigrants).

We sketch a simple model that captures heterogeneous fixed costs of hiring immigrants across firms and complementarity between natives and immigrants in production. We derive from it the interesting prediction that an increase in the immigrant supply in the area has larger 
positive effects on the immigrant share and consequently on the productivity, for those firms that initially hired no immigrants (revealing relatively high fixed costs of hiring them). Those firms were pushed above the threshold for which hiring immigrants is profitable and realized the largest gains. The model suggests that there is a cost threshold, depending on the wage of immigrants, below which firms will begin hiring immigrants (rather than only natives) and they will realize larger surplus and profits by doing so. This threshold is firm-specific if the cost of hiring immigrants varies across firms. When the supply of immigrants increases and their wage decreases at the regional level those firms that begin hiring immigrants will have the largest productivity gains. In general all firms hiring immigrants increase their surplus as immigrants wage decreases, but the largest effect will be for those with no immigrants initially.

Our empirical approach bases on manufacturing firms only because of data availability, and shows that a supply driven increase in immigration in a department raises the share of immigrants hired by firms as well as the share of firms hiring immigrants. Confirming the predictions of our simple model we find that the largest increase in immigrants as share of employment within areas of large immigration, is for the subset of firms that had initially no immigrants (or a very small share of immigrants) and ended the period with some immigrants. Then we show that for firms with low (or zero) initial shares of immigrants the positive productivity effect is the largest, as long as those firms hired some immigrants. These results are consistent with the cost-reducing role of immigrants combined with a fixed cost of hiring them that vary across firms. We then explore whether other outcomes, proxying for the productivity of the firm, were improved by hiring immigrants. We identify a significant effect on exports of the firm, a significant shift of native workers in the firms towards complex tasks, and a significant increase in level of capital used by firms. Even for these outcomes, in most cases, the strongest effect is for firms starting with no immigrants. These additional results are consistent with the idea that the productivity gains are consistent with improved skill to task specialization in the firm, improved export performance and potentially more capital-intensive production. We also show that there is no evidence of a decline in native 
wages in the firm as consequence of immigration. Rather, as a consequence of higher productivity, wages increased also for natives. These effects are not consistent with a world in which native and immigrants are perfect substitutes in production as in that case productivity should not be affected, capital intensity should decline, native wages should decline and native specialization should remain the same after the increase in immigrants.

The rest of the paper is organized as follows. Section 2 puts this paper in the context of the existing literature. Section 3 sketches a simple partial equilibrium model and derives some testable implications. Section 4 discusses the empirical specifications and the identification strategy and limitations. Section 5 presents the data and the summary statistics. Section 6 describes and comments on the estimates of the effects of immigration on firm outcomes. Section 7 concludes the paper.

\section{Literature Review}

While there is an abundance of studies about the effect of immigrants on the labor market outcome of natives ranging from the national level (e.g. Borjas 2003, Borjas and Katz 2007, Ottaviano and Peri 2012) to the area studies (such as Card 2001, 2009) and using data from several different countries ${ }^{3}$ (see also the recent literature reviews by Longhi et al (2005) and Kerr and Kerr (2011)), much less is known about the firm-level effect of immigrants. Some aggregate studies suggest interesting mechanisms through which immigrants may be absorbed within firms, by adjusting the task specialization of workers (Peri and Sparber 2009, Ottaviano Peri and Wright 2013) only few recent studies tackle this issue with actual firm level data.

Malchow-Moller, Munch and Skaksen (2012) using Swedish firms data find that immigrants strongly substitute for natives within the single firm. Differently Martins, Piracha and Varejao (2012) on Portuguese data find the opposite effects finding no effect of immigrants on the employment of natives at firm level. This studies focus only on the wage and employment

\footnotetext{
${ }^{3}$ Some countries are particulalry studied such as Germany (De New and Zimmermann 1994) and the UK (Dustmann, Fabbri and Preston 2005). A recent paper looking at the labor market effect of immigrant in France is Edo (2013).
} 
effect of immigrants. Importantly, however, these studies do not distinguish between an increase in immigrant supply at the regional level and at the firm level. While one can identify an exogenous shock (driven by aggregate country-specific flows) of immigrants into an area, it is very hard to think that the increase in the share of immigrants at the firm level is simply "supply-driven", not correlated, that is, with observable and unobservable characteristics of the firm. Spelling out the details of how the share of foreign-born employment in a firm is related to the local labor market supply and how it is related to firm's choice and characteristics is crucial and it is not done in these papers. Similarly Hatzigeorgiou and Lodefalk (2011), and Hiller (2013) analyze the effect of immigrants on the firm-level export, relying on a simple reduced-form empirical specification.

Recent studies suggest that immigrants produce a change in the local supply of specific skills (manual) and the consequent change in the specialization of natives, and the correlated adoption of productive techniques and investments by firms can change the total factor productivity and the capital intensity of firms (Peri and Sparber 2009, Lewis 2013). Productivity gains from immigration have been found across US states by Peri (2012). That paper shows that the main cause for those productivity gain from immigration was the specialization of native workers into communication-intensive tasks in which they have a comparative advantage and which are complementary to tasks performed by immigrant workers (mainly manual).

Very little attention has been devoted in the literature to the fact that a large share of firms does not hire any immigrant even in regions with very large immigrant presence (about $40 \%$ of firms do not hire any immigrant in our sample). On the other hand some of them hire a very large share. Immigrants, that is, just as exports (e.g. Bernard and Jensen 1999 ), are distributed very unevenly across firms. This suggests that there may be fixed costs associated to hiring immigrants as well as benefits that accrue to the firm if it hires immigrants up to a certain scale. It make sense to think that these costs may be related to the fact that information about immigrant workers is harder to read by firms and that integrating immigrants in production may require some basic arrangements (e.g. to improve 
communication) that some firms do not have in place. On the other hand for firms that have a low- fixed cost of hiring immigrants, (because they are better connected into their information network), there may be a productivity gain/ cost reducing effect from hiring them. The presence of fixed costs and firm heterogeneity has been very much at the center of the recent models of international trade (Melitz 2003, Bernard et al 2003). A large share of the manufacturing firms do not trade abroad, only larger and more productive firms trade abroad and the productivity effects of trade openness is in large part that of selecting higher productivity firms by increasing their advantage. Our paper moves some steps in the direction of thinking about immigration within the context of firms with fixed costs of hiring immigrants. Namely we combine the idea of complementarity between natives and immigrants at the firm level (e.g. Ottaviano and Peri, 2012) with the presence of heterogeneous fixed costs of hiring immigrants at the firm level. Both the theoretical and empirical literature in the area of immigration and the firm are in their infancy. A recent paper by Haas and Lucht (2013) uses a general equilibrium model with heterogeneous firms (Melitz 2003) where migrants imperfectly substitute for native workers and firms differ for their productivity levels; simulation results show that: (i) natives over migrants wage ratio increases with the immigrants share in the firm; (ii) firm productivity increases with the immigrants share in the firm. Trax et al (2013) is one of the few examples, to our knowledge, of empirical analysis of the impact of the country-of-birth diversity on plant productivity. Certainly with the increased availability of firm-level data it will become more common to focus on the theoretical and empirical analysis of immigration and the firm. This paper begins to think more rigorously about theoretical and empirical approaches.

\section{Theoretical Framework}

This section provides a simple intuition, based on a partial equilibrium model, of the impact of an increase in the local supply of immigrants on different firms in terms of their immigrant share, their profits and their productivity. The model combines two key ingredients: complementarity between natives and immigrants and the existence of fixed costs of hiring immigrants. These two ingredients deliver the key results. We formalize them in the simplest 
way possible.

Consider a fixed number of firms in a region (sector-region) producing a homogeneous good $y$ using local workers who can be native (indicated as $n$ ) or immigrant (indicated as $m$ ). These firms are heterogeneous as they differ in the cost of hiring immigrant workers. In particular there is a fixed cost (per unit of product) in hiring immigrants as those workers may be harder to reach or to train and firms need some familiarity with their network to hire them. The fixed cost of hiring immigrants might be also due to the screening cost to be paid by firm to discover the ability of the foreign born worker. Indeed, while domestic employers have perfect info about the ability of native workers, they do not have perfect information about the ability of immigrant workers (employers have good knowledge of the domestic, but not of the foreign education system). Once hired they can be used as an additional input in production and we assume that they are complementary to natives. Hence the production function of firm $i$ is:

$$
\begin{aligned}
& y_{i}=\theta\left(n_{i}^{\sigma}+m_{i}^{\sigma}\right)^{\frac{1}{\sigma}} \text { if } m_{i}>0 \\
& y_{i}=\theta n_{i} \text { if } m_{i}=0
\end{aligned}
$$

The terms $n_{i}$ and $m_{i}$ are the input of Natives and Immigrants in production of firm $i$. The term $\theta$ captures total factor productivity and $\sigma<1$ is a production parameter determining the elasticity of substitution between immigrants and natives. With only two factors in production $m$ and $n$ are complement (the increase in one factor's price decreases its demand and increases the demand of the other). In order to hire immigrants, and hence use the production function with two factors, a firm has to pay a fixed cost $f_{i}$ per unit of output. Firms differ in this cost, as they may have had different familiarity with immigrant networks and hence some may find it easier to recruit them. We assume that the distribution of the costs of hiring immigrants $f_{i}$ across firms is uniform between a minimum and a maximum $[0, F]$. 
Firms take the wage of natives, $w_{N}$ and immigrants $w_{M}$ (these are determined in the local labor market) as given and minimize costs of production. Assuming good $y$ as the numeraire, their unit cost will be:

$$
\begin{aligned}
\frac{\widetilde{w}}{\theta}+f_{i} & =\frac{\left(w_{N}^{\frac{\sigma}{\sigma-1}}+w_{M}^{\frac{\sigma}{\sigma-1}}\right)^{\frac{\sigma-1}{\sigma}}}{\theta}+f_{i} \text { if } m_{i}>0 \\
\frac{W_{N}}{\theta} \text { if } m_{i} & =0
\end{aligned}
$$

where $\widetilde{w}$ is the geometric average of the wage cost for natives and immigrants which is the solution to the unit cost minimization problem of the firm when it has access to both types of worker. Hence for firms whose cost of hiring immigrants is $f_{i}<\bar{f}=\frac{w_{N}-\widetilde{w}}{\theta}$ the unit cost of production is minimized by using the option of employing immigrants too. For those firms that hire immigrants the optimal proportion is a function of relative wages, that minimizes unit costs. In particular the optimal share $\left(s f_{-} \text {or }\right)_{i}^{*}$ of immigrants in employment of firm $i$ is:

$$
\begin{aligned}
& \left(s \text { f for }_{i}^{*}=\frac{m_{i}}{m_{i}+n_{i}}=\frac{\left(\frac{w_{M}}{w_{N}}\right)^{\frac{1}{\sigma-1}}}{1+\left(\frac{w_{M}}{w_{N}}\right)^{\frac{1}{\sigma-1}}} \text { if } f_{i}<\bar{f}\right. \\
& \left(s h \_f o r\right)_{i}^{*}=0 \text { if } f \geq \bar{f}
\end{aligned}
$$

The first part of condition (3) implies that in this simple model the share of immigrants $\left(s h f_{0}\right)_{i}^{*}$ is common to all firms that hire them and it increases as the relative wage of immigrants decreases. Assuming that native workers are perfectly mobile across firms and have no market power, their wages are pinned down by their productivity in the firms with no immigrants and hence $w_{N}=\theta$. Hence firms producing with the one factor technology will have 0 profits. On the other hand we also assume that immigrants are mobile across firms and have no market power, and they are paid their marginal productivity. Hence the 
profits of firms using both types of workers, per unit of output, will be: $\pi_{i}=p_{i}-\left(\frac{\widetilde{w}}{\theta}\right)-f_{i}$. Substituting $p_{i}=1$ (numeraire), $\widetilde{w}=w_{N}-\theta \bar{f}$ and $w_{N}=\theta$ we can write the fixed cost of the marginal firm, $\bar{f}$, indifferent between producing with or without immigrants as:

$$
\bar{f}=1-\frac{\widetilde{w}}{\theta}
$$

The share of firms employing a positive share of immigrants, call it $s h_{(i m m>0)}$ is equal to $\bar{f} / F$.

Finally substituting all the exogenous parameters in the profit for firm $i$ we get:

$$
\pi_{i}=1-\frac{\widetilde{w}}{\theta}-f_{i}
$$

Expression (5) show that, for a given number of firms and a given distribution of fixed costs $f_{i}$ the firm with the threshold cost $\bar{f}$ for hiring immigrants will have 0 profits (as those hiring only natives). Across firms, the profit per unit of output increase as fixed costs of hiring immigrants decrease. Firms that are more efficient in hiring immigrants (low $\left.f_{i}\right)$ will enjoy larger unit profits and employ a positive share $\left(s h \_f o r\right)_{i}^{*}$ of immigrants. Notice also that in our simple model profit per unit of output in a firm is a measure of unit productivity of workers as it represent the revenue net of cost per unit of output.

Consider now these firms as wage takers relative to $w_{M}$ on the local market (because there are several other firms and sectors in the region). From conditions (3)-(5) we obtain the following predictions.

- Prediction 1: A decrease in $w_{M}$ (possibly due to an increase in the supply of foreign-born) will decrease $\widetilde{w}$ and hence it will increase the threshold (straightforward from equation 4) and some firms will begin hiring immigrants. Hence the share of firms in the region hiring a positive number of immigrants, $s h_{(i m m>0)}$ will increase.

- Prediction 2: A decrease in $w_{M}$ will increase the share of immigrants hired by those each firm with positive immigrant share (see condition 3) as $\left(s h_{-} \text {for }\right)_{i}^{*}$ depends negatively on the ratio $\frac{w_{M}}{w_{N}}$. 
- Prediction 3: An increase in the share of immigrants in a firm subsequent to a decrease in $W_{M}$ will be larger for those marginal firms with originally no immigrants. They will go from 0 to $\left(s h \_f o r\right)_{i}^{*}$ while the other firms will experience a marginal increase in $\left(s h{ }_{-} \text {for }\right)_{i}^{*}$.

- Prediction 4: A decrease in $w_{M}$ will increase the profits and hence measured productivity of firms that hire immigrants. The profit per unit of output (revenue net of costs) represents the surplus of each firm hiring immigrants, (equation 5) and it increases as $\widetilde{w}$ declines. Moreover firms that move from 0 immigrants to positive values will also experience a substantial increase in their surplus before they pay for the fixed cost from an initial value of 0 . The increase in productivity will be larger for firms moving from 0 to positive values of immigrants than for the other firms.

While our model is partial equilibrium and very simple it provides some predictions that are straightforward consequences of the complementarity between native and immigrants and of the existence of a fixed costs in hiring immigrants, which is heterogeneous across firms. In our empirical analysis we will test the impact of an exogenous increase in the local supply of immigrants which reduces their wages on surplus and performance of a firm.

First, we will check whether, as predicted in the model above, a positive immigration shock increases the share of immigrants in some firms, decreases the share of firms with no immigrants, and has the largest effect on firms with initially zero (or extremely low) shares of immigrants (Prediction 1-3). Then we check whether the firms with larger increase in immigrants shares had productivity (surplus) changes and whether this effect is stronger for firms with initially no (or very few) immigrants. Finally we test whether other features of production often associated with higher productivity are also adjusted to the inflow of immigrants such as the specialization of natives in complex tasks and the export of the firms both in terms of values sold (intensive margin) and number of markets (extensive margin) and wether these effects are stronger, for firms starting with a zero and increasing their share of immigrants. 


\section{Empirical Framework}

Our empirical strategy is set up to test the predictions of our simple model. The empirical specifications, however, are quite general and go well beyond that model. The goal of the empirical analysis is to help us understand the response of firms' outcomes to inflows of immigrants in the local area. In particular we set up an empirical model that, controlling for firm heterogeneity, analyzes the response of firm outcomes to regional immigration shocks. We also allows firms that initially had no (or very few) immigrants to respond to these shocks in different way than those that already employed immigrants; the rationale for this heterogeneous effect lies on the idea that firms with no immigrants, after a reduction in the wage for immigrants, can afford the fixed cost for hiring them and move to the "better" technology that employs a mix between native and immigrants.

Our framework allows us to emphasize that the area-level change in immigrants, appropriately instrumented, can be considered as a supply shock, exogenous to the firm. However the change in the firms' employment share of immigrants is the result of an interaction between this shock and the characteristics of the firm (i.e. fixed cost in hiring immigrants in our interpretation). Hence, different regions provide variation in the intensity of the supplyshock while different firms within the region provide heterogeneous response to it in the hiring of immigrants and in other outcomes. The few previous studies on the impact of immigrants at the firm level (e.g. Malchow-Moller, Munch and Skaksen, (2012), Martins, Piracha and Varejao (2012)) have combined the heterogeneity of firm responses and the variation of immigrant shock across localities by analyzing the response of firm outcomes to changes in firm's share of immigrants. As we will show this may confound the intensity of the local shock with the type of firms on which the shock has the strongest effect. The trade literature has also related export shocks to wage (productivity) effects in the firm. In that context (e.g. Hummels et al 2013) it makes sense to consider a firm-specific export (or import) shock, because the differences in export/import markets of firms make them differentially vulnerable to the growth of those markets, even for firms located in the same area. To the contrary as immigration shocks are changes in the local availability of immigrant 
workers they are common to all establishments in an area. Then individual firms can respond differently according to their differential cost of hiring immigrants (as shown in the model) and this is what we allow.

Our baseline empirical model is as follows:

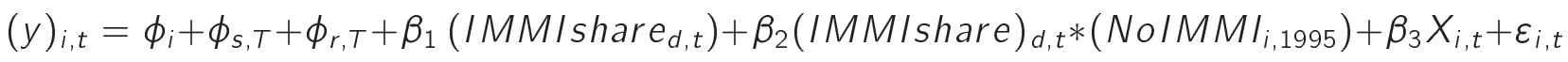

Where $i$ indicates the firm and $(y)_{i, t}$ represents a placeholder for different firm-level outcomes, beginning with immigrants as share of employment, in firm $i$ and year $t$ and then considering measures of productivity, specialization, export and wages. Our sample includes the universe of manufacturing firms in France ${ }^{4}$ between 1995 and 2005 hence the index $t$ takes values between 1995 and 2005. The term $\phi_{i}$ captures a set of firm fixed effects, while $\phi_{s, T}$ and $\phi_{r, T}$ are sector and region specific time trends respectively. The firm fixed effects are meant to capture all the unobserved firm specific and sector-region specific factors affecting the outcomes of firms (i.e. regional agglomeration effect or sector technological shocks). ${ }^{5}$ Sector and region specific time trend are meant to capture the differential tendencies over time of sectors and regions, potentially correlated with migration and productivity ${ }^{6}$.

The term $X_{i, t}$ captures a set of firm-specific time-varying controls including the head-quarter dummy (being one if the firm is the head-quarter of a group), a foreign affiliate dummy (being one if the firm is an affiliate of a foreign multinational firms) and the firm age. The explanatory variables of interest are $/ \mathrm{MM} /$ share $_{d, t}$, capturing the share of immigrants in the district $d$, where the firm is located ${ }^{7}$, and year $t$ and the interaction between that variable

\footnotetext{
${ }^{4}$ As described in the data section, we however rely on manufacturing firms with at least 20 employees, i.e. firms for which we have balance sheet data from EAE.

${ }^{5}$ Indeed, in our sample each firm belongs to a specific region-sector over the entire period. For multi-plant firms operating in several sectors and regions, we keep the sector and the department of the biggest plant (in terms of total number of workers). Further we dropped those firms changing sector of region over the period.

${ }^{6}$ One important shock in the French labor market might be represented by the EU enlargement toward Easter countries in 2004 (free mobility of workers within EU). however France implemented the free mobility of people from Eastern countries only in 2008, thus out of our sample.

${ }^{7}$ We consider the 95 non-overseas departments of France. The explanatory variable of interest, IMMIshare,
} 
and a dummy No/MMI $\mathrm{N}_{i, 1995}$ equal to 1 if firm $i$ had no immigrants at the beginning of the period, in 1995. Notice that the change of immigrant share captures the district-level change in immigrants, while the dummy allows firms that initially have no immigrants to respond differently in their outcome, to such a shock. The model predicts that those firm with no immigrants in 1995, which later hired them, increased their share significantly more than firms that already had them (effect of fixed costs), and experience larger productivity changes. This would imply a positive and significant $\beta_{2}$ coefficient. $\varepsilon_{i, t}$ is a random error not correlated with the dependent variables.

We analyze five main outcomes, $(y)_{i, t}$ at the firm level. They are the share of foreign-born in employment, the logarithm of total factor productivity (TFP), the logarithm of the capital stock, an index of specialization of natives in occupations involving complex tasks and the logarithm of exports. First we consider the TFP of firms and we compute it using the Olley and Pakes (1996) - OP from now on - approach. We also used as a robustness check TFP calculated following the Levinsohn and Petrin (2003) - LP - approach. The results using this second method of calculating the TFP are in the Appendix. The OP approach consists of a semi-parametric estimator using investment by firm to proxy for unobserved productivity shocks. This allows to solve the simultaneity problem between inputs and output. The OP procedure also defines an exit rule to solve for the selection issue in TFP estimation. Since OP relies on investments to proxy for productivity shock (with investment increasing in productivity), only observations with positive investment values could be used ${ }^{8}$. See appendix section A.2 for further details on TFP calculation.

The log capital of the firm has been computed as the logarithm of the reported value of capital assets for the firm. For the task specialization of natives we used two measures. First we focus on the communication complexity and then on the cognitive complexity of tasks covered by natives. Following Peri and Sparber (2009) we consider the occupation of each

\footnotetext{
takes 1045 different values (95 departments by eleven years).

${ }^{8}$ To make sure that the selection of firms with positive investments does not affect results we also perform the LP approach which uses intermediate inputs as proxy for productivity shocks. In this way we can get TFP for those firms reporting zero (or negative) investment values. See also Van Beveren (2010) for a detailed discussion of OP and LP estimators.
} 
worker in the dataset and we compute the index of communication, cognitive and manual intensity of the occupation using the O*NET (Bureau of Labor Statistics) cross-walked to the ISCO88 definition of occupations. These variables give the intensity of one occupation in the use of a specific skill (such as language comprehension, oral expression, etc .), then such intensities have been grouped into three broad skills: manual, communication and cognitive activities and finally they are expressed as (log of) communication (or cognitive) divided by manual intensity. The logarithm of the ratio of communication to manual is the first index of complexity of skills, while the log of the ratio of the analytical to the manual index is the other. $^{9}$

Finally to capture the export performance of firms, we used two related measures of exports. First we consider the total value of export as the log of exported values by exporting firm. Second we use a measure of only the extensive margin of export, namely the number of destination markets served by the firm ${ }^{10}$. These last variables are potentially all correlated to productivity. They identify channels through which a firm increases productivity (such as the specialization variable) or they may be outcomes revealing higher productivity (export performance). Testing the impact of immigrants on each one of them is a way to strengthen and qualify our results. For all the productivity-related outcomes the model predicts a positive and significant value of $\beta_{1}$ and a positive and significant value of $\beta_{2}$.

Our model has very different implications on outcomes for firms that initially had a 0 share of immigrants and then hired them. Namely all the productivity-related effects should be stronger than average for firms beginning with 0 immigrants and hiring some of them. In order to identify such heterogeneous effects, we run specification 6 on all firms that have at least one immigrant by the last year of observation to distinguish the overall effect of an increase in immigrant supply from the specific effect on firms with no initial presence of immigrants. ${ }^{11}$ Then, as robustness check, we run the same equation as in (6) on the full

\footnotetext{
${ }^{9}$ See data section for further details on how complexity measures have been computed. Appendix section A.3 reports more detailed description of how we built such indices. Finally, in Table A. 6 we show these measures by (2-digit) occupation.

${ }^{10}$ As a check we also used the number of varieties exported by firm (as the number of HS6 level products exported by firms).

${ }^{11}$ As a robustness check we use a different sample composed by firms that have at some point hired one
} 
sample of firms.

\subsection{Identification issues and Instrumental Variables}

Estimating equation (6) with least squares, even in the presence of several fixed effects and controls, leaves open the possibility that some omitted local conditions may affect simultaneously the demand of immigrants and the productivity of firms. District-specific productivity shocks, not observable to the researcher, may drive a positive correlation between the residual of the productivity equation, $\varepsilon_{i, t}$ and the explanatory variable $/ M M /$ share $_{d, t}$. In our setting the omitted variable concern seems more severe than the reverse causality problem because the unobserved productivity shocks of an individual firm, do not have a significant impact on the district's economic outcome which is much larger. In order to identify the part of the change in the immigration share at the district level that is driven by supply changes rather than by local productivity shocks we use the shift-share instrument based on initial spatial distribution of immigrants. Pioneered by Altonji and Card (1991) and then used in several studies since, (such as Card (2001), Card (2009), Peri and Sparber (2009), Lewis (2013) among others) this approach is based on the idea that new immigrants (especially with lower levels of schooling) tend to move to the same area (department) where previous immigrants from the same country of origin already live and have established a community ${ }^{12}$. This is because they know of opportunities in those location from the network of immigrants and because they may enjoy the amenities of living with their co-nationals. Hence we use immigrants in each French department as share of total immigrants in the first year of our data, 1995, and we then apportion the growth in the total number of immigrants in each year proportionally to that share obtaining an imputed number of immigrants in each department, which we call $\widehat{\mathrm{MMI}_{d, t}}$ and is calculated as:

$$
\widehat{\mid M M I}_{d, t}=\frac{\mid M M I_{d, 1995}}{\mid M M I_{\text {France, } 1995}} * \mid M M I_{\text {France }, t}
$$

immigrant. Results, available under request, do not change.

${ }^{12}$ In our data we have no info on the country of origin of migrants to compute the country-specific imputed number of migrants, hence we implement the instrument for their aggregate. 
We then computed the share of imputed migrants in the department as follows:

$$
\text { IMMIshare }_{d, t}=\frac{\mid \widehat{M M I}_{d, t}}{\mid \widehat{M M I}_{d, t}+\text { Natives }_{d, 1995}}
$$

Notice that in (8) the population growth of natives in the department (which is also potentially endogenous) does not enter the imputed share in year $t$ as native population, in the computation of the share, is fixed at year 1995. The instrument captures the idea that department with a large initial share of immigrants (as of 1995) are likely to host a large share of the new immigrants because of network effect and family reunion of migrants (years from 1996 on). The implicit assumption is that the distribution of immigrants in 1995 across departments is uncorrelated (or weakly correlated) with the distribution of demand shocks in the department after 1995, once we have controlled for a firm fixed effects and region (sector) specific trend.

The assumption that the distribution of immigrants in year 1995 is orthogonal to subsequent productivity and labor demand shock at the local level is strong. Persistent income and productivity shock may have affected the stock of immigrants in 1995 and may be correlated to flows after 1995 . To find some reassurance that the instrument constructed this way is not correlated with pre-existing economic patterns across districts we consider the correlation across districts between our instrument, namely the average change in the imputed immigrants between 1996-2005 13 and the 1995 level of the average firm's economic outcomes that we will analyze in the empirical section (TFP, Specialization in Complex Tasks by natives, Capital and Trade). The issue is whether our instrument is correlated with the pre-existing performance of firms across districts. Table 1 shows the simple OLS correlation across districts of those variables and, reassuringly, it finds no significant correlation with pre-existing economic outcomes. While we are unable to assess the correlation of the instrument with unobserved pre-determined factors, it is reassuring to know that there is no correlation with the pre-period economic outcomes. The inclusion in the regression of firm fixed effects and region and industry trends also help clean the residual from unobserved local

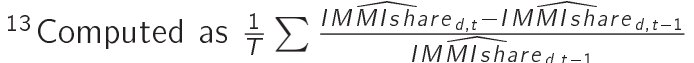


economic performance.

The power of the instrument, expressed by the F-statistics of the first stage will be shown at the bottom of each regression table from 3 to 10 . As we will notice the F-stat is very high, often around 80 and never even close to the threshold of 10 , usually used as rule of thumb value for triggering concerns of weak instruments. This also limit any concern of weak instruments. ${ }^{14}$ In estimating the interaction term in equations (6) we also address the issue of endogeneity of the interacted variables by using the imputed share of immigrants in the department interacted with the relevant dummy for the presence of migrants in 1995 . The feature of having no-immigrants in 1995 is pre-determined and we think of it as an indication of idiosyncratically high costs of hiring immigrants.

\section{Data and Summary Statistics}

Our first data source in constructing the relevant firm-level variables is the DADS (Declaration Annuelle des Donnetes Sociales) databases. It consists of administrative files based on mandatory reports on the employees' earnings and characteristics made by French firms to the Fiscal Administration. DADS data contains yearly information about the structure of employment for each establishment in France. This database includes different units organized by year and region (12 years- 24 regions) which implies that 288 separate databases with more than 50 millions of observations by year were merged. In each dataset the single observation corresponds to a unique employee-year-establishment so that we can reconstruct the exact employment structure of each establishment. At the establishment level DADS provides information on the geographical location and the industry of the establishment, as well as the identification number that corresponds to the establishment (SIRET) and the identification number that corresponds to the parent enterprise (SIREN).

\footnotetext{
${ }^{14} \mathrm{As}$ a preliminary test of the relevance of our instrument (rigorous test using F-test is showed in each table 3-10) we compute the correlation between the 1995's distribution of immigrants across department, with the distributions at $t=1996, \ldots, 2005$. We obtain very strong positive correlation between 1995's and the following years' distribution. This shows that departments having high share of immigrants in 1995 are (approximately) the same departments with high share of immigrants from 1996 to 2005 - which is the rationale at the base of our instrument. As an example, table A8 shows positive correlation between the share of immigrants across department in 1995 and 2005.
} 
As for the employees characteristics, we have information on the gender, age, place of birth (native vs. foreigners), total gross and net earnings during the year, number of hours worked and main occupation (both at two-digit CS and four-digit PCS-ESE classification). Individual employees are not linked across years and hence we cannot construct a panel of individuals. However we can reconstruct a longitudinal panel of establishments and we can construct the characteristics of employees by firm (SIREN) each year.

In order to measure whether native and foreign workers specialize in different production tasks we combine task-level data from the Standard Occupational Classification (SOC) system by O*NET dataset with the occupational structure of French provided by the DADS database described above. Our aim is to construct an indicator of the complexity of tasks performed by native workers within each French firm over time. We use the 2010 version of O*NET dataset which includes measures of the importance, on a scale from 0 to 100 , of more than 200 skills (e.g. finger dexterity, oral expression, thinking creatively, operating machines) in all the six-digit Standard Occupational Classification (SOC) of occupations. We follow Peri and Sparber (2009), and we focus on the dichotomy communication versus manual tasks, as our index of how complex a task is. For the definition of manual skills we average 19 O*NET variables capturing an occupation movement, coordination and strength requirements. For the communication intensity index we average $4 \mathrm{O} * \mathrm{NET}$ variables considering oral and written expression and comprehension. For the cognitive task we use $10 \mathrm{O} *$ NET variables capturing the analytical skills used. Once we have associated our complexity measure to an occupation, we construct the measure of skill complexity of native workers at the firm level using the DADS dataset. As the occupational classification in DADS is specific to France we have to do the merge by converting both occupational classifications into a common nomenclature, that is the 1988 International Standard Classification of Occupations (ISCO -88) ${ }^{15}$.

To construct the variables that capture firm outcome we also use two additional data sources. All the trade variables we use in the paper come from the Custom dataset, which provides records of all the French firms exporting goods during the period 1995-2005. Exports -

\footnotetext{
${ }^{15}$ For a detailed description of the procedure adopted to merge occupations and calculate the occupation-specific skill intensity see the Appendix A.3. Table A.6 shows complexity measures for 2-digit level occupations.
} 
quantity in tons and values in Euros are available by firm, year, product (identified by an 8 digit code corresponding to the NC8 nomenclature) and the country of destination and origin, respectively ${ }^{16}$. The other source we use is the Annual Business survey (EAE). It gives us balance-sheet data information (e.g. value-added, sales, value of the assets included in the capital stock, use of intermediate goods) necessary to compute TFP measures at the firm level. Unfortunately this last source covers only the manufacturing sector, and firms with more than 20 employees. Data are available for the period 1995-2007. Matching all these sources together, using the SIREN identification number, we got an unbalanced panel dataset over the period 1995-2005. Finally the data about the immigrant and the native population in a department are from (department-year) aggregation of DADS individual data. Thus we obtain the total number of immigrant and native workers in the department in the year.

The summary statistics of the outcome variables and of the share of foreign-born at the firm level are reported in Table 2. The related correlation matrix are reported Appendix Table A1. Firms vary substantially in size and average wage and also in their share of immigrants with about $60 \%$ of them (firm-year) having 0 immigrant share. On the other hand, to give an idea about the distribution of immigrants across French regions, we provide Table A2 in the appendix, showing immigrants as share of the population. What appears immediately is that the period we consider is one of very significant increase in foreign-born (from $5 \%$ to $15 \%$ of the population) and that different regions have very different exposure to immigrants: Ile de France and Provence-Alpes-Cote D'Azur have high share of migrant workers up to 18 and $15 \%$ respectively, while in regions such as Basse-Normandie the share of migrants workers is only $4 \%$.

\section{The Effects of District Immigrant on Firms}

Tables 3 to 9 show the estimated parameters on the explanatory variables of interest for specifications (6) using two samples of firms. The first sample, in columns $1-4$, includes only

\footnotetext{
${ }^{16}$ For the number of products exported one needs to account for the fact that the product nomenclature changes over time during the period considered. To avoid the problem of mistaking a change in code for a change in product we harmonized the product nomenclature in the dataset, expressing all export and imports at the HS6 1996 revision.
} 
firms having at least one immigrant by the last period of observation; this is useful since the effect of local migration shocks is supposed to be restricted to those firms having at least one immigrant. ${ }^{17}$ The second sample, columns 5-6, is the full sample of firms in our dataset, it is intended as a robustness check here.

Tables 3 to 9 share a very similar structure. We will describe the main features of the table when describing Table 3 and then comment on each Table in the following subsections.

\subsection{Firm's Share of Immigrants in Employment}

In Table 3 we show how the increased share of immigrants in the district population translate onto local firms hiring more of them. The dependent variable in specifications (1)-(4) is the employment share of immigrants in the firm and the unit of observations are firm-years. In the first column, specification (1), we report the coefficient on the district share of immigrants from a specification that includes the fixed effects and the control variables but it does not include the interaction with the dummies. The estimates are obtained using least squares. The second column, and all the following ones, shows the same coefficient estimated using 2SLS with the imputed share of immigrants described above as instrument. Then in column (3) we show the key coefficients in the full specification including the interaction between the share of immigrants in the department and the dummy equal to one if the firm had no immigrants in 1995. In column (4) rather than interacting with a dummy denoting exactly no immigrants in 1995 we interact with one capturing firms with very few immigrants (below the median value of firms immigrants share, which was $2.3 \%$ in 1995). In all cases the sample used for the regression includes firms that had at least one immigrant by the last period of observation as those firms that never had immigrants do not contribute to identify these effects. The standard errors are clustered by district level in each specification in order to account for the correlation of errors across firms and over time within a geographic department. These regressions are simply meant to establish whether firms with initially no (or few) immigrants responded to the exogenous changes in the local immigrant supply

\footnotetext{
${ }^{17}$ As an alternative sample, intended as robustness check, we also use a sample of firms having hired at least one immigrant in the period. Results, available under request, do not change.
} 
differently than other firms. ${ }^{18}$ With no fixed costs of hiring immigrants, and a firm-level network, one should expect that new immigrants are hired across firms in proportion of existing ones. This would imply larger share growth in firms with larger initial share, and hence a negative coefficient on the interaction effect. The model presented above, instead, predicts the opposite effect. With fixed costs and an optimal combination native-immigrants for production, some firms will move from 0 to the optimal share, when supply increases and the cost of immigrants decreases, showing larger increase than firms already employing immigrants.

We see that, because of the power of the instrument, the 2SLS estimates are precise and significant. They are also larger than the OLS estimates revealing the potential existence of a measurement error bias stronger than the endogeneity bias. More interestingly, we find that the effect of an increase in immigrants by one percentage point of the population in the department translates into an increase in the share of immigrants in firms by 0.72 percentage points on average, (column 2). When separating firms with initially 0 immigrants we find that those, experienced an extra effect from District immigration by almost 0.45 percentage points on their immigrant share. Firms with no initial immigrant employed increased their immigrants by 1.1 percentage points of employment for each increase of immigrants by one percentage point in the district population. For firms already hiring immigrants that increase was only 0.65 percentage points. Hence, the coefficients show that while all firms that hire immigrants respond to a higher share of immigrants in the population by increasing their share in employment, firms that initially had no immigrants (or very few of them) respond significantly more. Column (4) shows that the differential response of firm with very few immigrants in 1995. Similarly to the case of initially 0 immigrants firms with few immigrants have a response $100 \%$ larger (sum of main and interaction coefficient) than the response of firms with larger immigrant shares in 1995. Specification (1)-(4) test propositions 2 and 3 of Section (3). Those results establish that while firms increase their share of immigrants when more of them are available in the district (and their wage is lower), the firms with

\footnotetext{
${ }^{18}$ Preliminary descriptive evidence reported in Table A9 supports such feature: firms having no immigrants in the starting year (1995) experienced (on average) bigger increases in their immigrants share than other firms.
} 
initially no immigrants seem to adjust their share more significantly. This is consistent with the existence of an optimal native/immigrant ratio in the firm and fixed costs of first hiring immigrants, as illustrated by our simple model. In order to test proposition (1) we want to see whether in districts with increasing supply of immigrants, the share of firms with non-zero immigrant in employment also increases. In specification (5) we do this in a regression that still uses the firm-level structure. The dependent variable is a dummy equal to 0 if the firm has no immigrants and equal to 1 if the firms move to a positive share of immigrants (i.e dummy equal to one if no immigrants at time $t-1$ and some immigrants - at least one at time $t$ ). The positive and significant effect of the share of district immigrants on this variable implies higher probability for firms in districts with high immigration, that they begin hiring immigrants. Regression in column (6) tests directly proposition 1 at the department level. Using the share of firms with non-zero immigrants in employment calculated for a department we regress that on the share of immigrants in the workforce. Again there is clear support for the idea that a larger local supply of immigrant increases the share of firms that hire them.

\subsection{Firms' TFP growth}

Table 4 shows the estimated effects of district immigration on firm TFP. The first two specifications show the average effect, estimated in OLS and using 2SLS. Increased immigration in the district is associated with faster TFP growth of the firms. We present in this Table the results obtained using the Olley and Pakes methodology. Table A3 in the appendix shows the corresponding results using the Levinsohn and Petrin procedure to calculate TFP. The effect estimated using 2SLS is significantly larger than the OLS effect and very precise. Endogeneity concerns, therefore, do not seem to play a role in the estimation of the effects on firm productivity. The estimates of column 2 imply that increase in the immigrants as percentage of employment in the district by 10\% (which is roughly the average between 1995 and 2005), would correspond to a 2.7 log point increases (about 2.7 percent) in the TFP of the average firm in the district. Column (3) and (4) show that the effect on TFP is significantly stronger for firms with initially no immigrants (3) or a very small share of immigrants (4). Using the 
estimates in column (3) a firm with initially no immigrants will receive a benefit of $3.5 \mathrm{log}$ points for each increase in the immigrant population in the district by $10 \%$ of employment. This effect is crucially linked to the fact that this firms hire the immigrants, and they hire them at a faster pace than other firms in the district (as shown in Table 3 above).

In order to confirm the crucial role of hiring immigrants for realizing the productivity gains in a district we consider in specification 5-6 all firms, not only those with some immigrants. The overall average effect (column 5) is almost the same as that in column (2). More importantly in this case we estimate one specification as (6) in which we include the interaction with no initial immigrants (specification 6). Specification (6) confirms the results obtained in column (3), restricted to the sample of firms with at least one immigrant by the end of the period. Firms hiring immigrants realize the complementarity in production. They may also set in motion other productive adjustments such as more investment, more specialization and better technology. We will analyze these outcomes in the next sections.

\subsection{Firms' Capital growth}

The significant increase in productivity at the firm level identified in the previous section is likely to drive other changes in firms' outcomes. In particular while in our model we do not have a capital factor, if we think that immigrants are complementary to capital too then we would also observe growth of the firm's capital stock and potentially of capital intensity. On the other hand if immigration is only a shift in supply of labor to the firm then capital may not respond and the capital/labor ratio at the firm's level may decrease. Moreover if firms switch to a different production function that is immigrant-intensive this may imply a change in capital. Lewis (2011) finds that in high immigration areas firms are associated with slower growth in capital-labor ratio. It is interesting therefore, to see wether in our case the impact on TFP has a similar impact on investment.

Table 5 shows the estimates of specifications similar to those in Table 4, when the dependent variable is the logarithm of capital value. As we always estimate the specifications with firm fixed effects the coefficients tell us whether larger immigration shares in the district stimulate 
higher net investment in the firm. Column (1) and (2) show a positive and significant effect on the capital of the average firm. The 2SLS estimate implies that an increase of immigrant percentage in employment by 10 points increases the capital stock in the average firm by almost $20 \%$. The effect is much stronger (in percentage terms) than the effect on productivity. Firm accompany the hiring of immigrants with significant capital investments. Columns (3) and (4) confirm also that the effect of district immigration on capital investment is much stronger for those firms with initially no immigrant, or with very small initial share of immigrants (below the median). Their elasticity of response to district immigration is about the $33 \%$ bigger than the response of the other firms. These effects are significant both when considering only firms with at least one immigrant by the end of period (specifications 3-4) and when considering all firms (specification 5-6).

Measures of the capital stock and of its value can be imprecise. In the appendix we also use a much coarser, but much easier to collect, measure of the capital stock of a firm, namely the number of plants that the firm operates. Table A4 shows the impact of district immigration on the logarithm of the number of plants that a firm operates, distinguishing as usual between those increasing their share from 0 , and those not hiring any immigrants. As for the measure of capital stock we find that the average effect on firms' plants is positive and it is stronger for (almost restricted to) those firm beginning at 0 immigrants. Immigrants seem to affect the total value of capital as well as the number of plants that a firm operates. One way to increase productivity in the presence of immigrants may be the increased opportunity for operating new plants.

\subsection{Task specialization of natives}

As a further margin of potential response at the firm level we consider the specialization of native workers. The complementarity from immigrants may come from their preferential specialization in some tasks. Several papers suggest that they are intensively employed in Manual tasks, possibly because their comparative disadvantage in language skills (Lewis 2013). It is therefore interesting to analyze whether the specialization response of natives 
in a firm is also part of the margin of adjustment for the firm. Following Peri and Sparber (2009) we construct two possible indices of Complexity for the occupations of natives in the firm. The first is the logarithm of the ratio of the index of communication and the index of manual intensity of native occupation. This index take high values if natives are more concentrated in occupations that use intensively communication skills (such as sales jobs, secretarial types of jobs and usually white collar ones) relative to manual skills (machine operators, laborers or blue collar jobs). An alternative is to consider the ratio of cognitive intensity (managers, human resources officers, engineers) to the same manual intensity as measure of complexity of jobs.

The indices are obtained using the occupational distribution of natives in a firm and are correlated to each other. A positive change in these two indices indicate mobility of workers towards jobs using more cognitive complex skills and away from manual-intensive skills. Table 6 and 7 show the estimated coefficients using those two indices as dependent variable and they provide a similar picture, hence we will comment on those results at the same time. Both OLS and the 2SLS estimates point to a positive effect of the district immigration on the cognitive specialization of natives in the firm, they do not find a stronger effect for firms initially hiring no immigrants. While the interactions effects in specifications (3) and (4) and in specification (6) have a positive coefficient that value is never significant at the standard confidence levels. This may indicate that in most firms in districts with high immigration native workers move towards more cognitive intensive jobs, but this is a general response, not limited to firms that hire immigrants. If the competition between natives and immigrants is an attribute of the whole labor market it make sense to have native workers respond in similar way in all firms. After all the marginal productivity of a skill, if workers are mobile across firms, is affected throughout the market. Individual firms may have different productivity effects and still native workers may be affected in a similar way across firms. This, as we will see is mirrored in the analysis of the wage effects of immigrants on local natives.

The competition effect of immigrants in manual tasks appears to be a phenomenon that affects the whole local labor market in a similar way and hence natives move towards more 
complex occupations in all firms. The productivity and investment of firms, however, are affected more strongly if they hire immigrants, and those with initially no immigrants appear to be the firms with the largest increase in immigrants shares and productivity indicators.

\subsection{Firms' Export}

The productivity gain from immigration shown before could also be reflected in the export performances by firms. A large body of empirical literature (beginning with Bernard and Jensen 1999) has emphasized that only more productive firms are those that access international market and export. Moreover firms that export in many different markets are the most productive ones (because they are able to cover the fixed cost of entry in new markets). At the same time several papers have analyzed the connection between immigration and exports at the national and regional level (see Felbermayr, Grossman and Kohler 2012 for a recent review) but only few of them so far have looked at the firm-level connection between the two (Hiller 2013 and Hatzigeorgiou and Lodefalk 2011 show this effect using Danish and Swedish data respectively). Most studies find that immigrants have a trade-creation effects on regions and firms and interpret this as the result of reducing fixed costs of trading with the country of origin of immigrants (e.g. Peri and Requena 2010). In a firm level (trade) framework, if the trade creation effect of immigrants were due to only the reduced fixed cost to export (i.e. supplementary information on destination countries provided by immigrants), we would observe only a positive effect of immigrants on the extensive margins (number of markets) and a null effect on the intensive margin (since the intensive margin is affected only by changes in variable trade cost). So, this section aims also to shed light on the channels through which immigrants boost trade.

In our analysis we have not information on the country of origin of immigrant workers, hence we cannot properly test the information channel driving the pro-trade effect of immigration. However, considering the value of trade as affected by firm productivity we consider it as outcome in specifications similar to those tested in the previous tables.

In table Table 8 we report estimation results when the logarithm of the total value of exports 
by the firm is the dependent variable. In Table 9 we consider the logarithm of the number of export markets of the firm (extensive margin only) as outcome. Very interestingly, in Table 8 the 2SLS estimated effects of district immigrants on firm export is large and significant. An increase of immigrants by 10 percentage points of the local population increases exports of the firm in the district by $14 \%$. Firms initially at 0 immigrants show a positive (but not significant) effect on the interaction (column 3 and 6). Hence in districts with growing immigrants community, firms that hire some of them experience a clear increase in the volume of exports.

The results of Table 9 are also interesting. While the aggregate effect on export could be driven by a simple increase in trade flows, in Table 9 we analyze whether immigration increases also the number of foreign markets served by the firm. If we think that immigrants, besides affecting productivity, reduce the fixed costs of exporting in new markets this second effect could be positive. The positive and significant effect of immigration on the number of export market found in specification (2) of Table 9 is particularly strong for those firms increasing their share significantly, from an initial value of 0 (column 3) or from a very small initial share (column 4). As immigrants flow in the district firms can open up new export markets and those that hire more immigrants (likely from different countries) beginning from a small share and increasing it, open up more markets. This can be the combined effect of higher productivity and of lower fixed costs of accessing export markets. Overall the effects on export are consistent with those on productivity and show that immigration in the district affects firms's export performance, especially those firms that increase significantly their share of immigrants from 0 . Immigrants increase the value of their exports and the number of their foreign markets ${ }^{19}$.

\subsection{Native Wages}

So far we have not even considered the variable on which most of the existing studies of immigration effects focus: wages of natives. In a framework similar to that of the other firm-

\footnotetext{
${ }^{19}$ Table A5 in the appendix shows similar results as Table 9, using the number of exported variaties (rather than the number of foreign markets) for multi-product plant. Immigrants also increase the variety of goods exported by a firm.
} 
level outcomes we consider the logarithm of wages to native workers as dependent variable and we report the estimated coefficients in Table 10. Wages are measured at the firm level and hence their changes combine changes in wages of individuals and potential changes in the composition of workers in the firm. First keep in mind that a key mechanism operating in reducing the firm's costs when hiring immigrants is their complementarity to natives. Hence, while our model predicts no wage effects for natives, as the productivity in their outside option (linear technology) does not depend on immigrant supply, in a more general setting we can think that their wages in the region can be increased by complementary immigrants. Moreover if the market for native and immigrant workers is the whole district and not a single firm (as in our model), the effect may be common to all workers and not differentiated by firm. The results of table 10 are consistent with this interpretation. An increase in the immigrant share in the district seems to have a strong positive effect on the average wage of natives in local firms. An increase of immigrants by 10 percentage points of employment would increase native wages in the firm by $11 \%$ (column 2 of Table 10). Moreover the effect on native wages in firms hiring more (column 3 and 5) or no immigrants (column 6) does not seem to be significantly different. These effect may be due in part to a selection of skilled natives in firms with immigrants and may combine different wage effects for workers of different skill levels.

\subsection{Effects along the firms' TFP-distribution}

We have shown in the previous section that firms with initially low share of immigrants (or no immigrants at all) are those positioned to benefit the most from immigration in the district, as they take advantage of it by hiring new immigrants. If firms with initially no immigrants are those with lower productivity, then the estimated response suggests that immigration promotes the potential for less productive firms to catch-up with more productive ones. Specifically we would like to analyze the estimated effect of immigration in the district allowing for it to differ across the initial distribution of firms according to their TFP.

In analyzing this question we follow the approach by Dustman, Frattini and Preston (2013) 
who analyze the impact of immigrants on native wages allowing for the effect to vary across different segments of the native wage distribution. In our case, for each department-sectoryear we compute the TFP distribution across firms. Then we regress the department-sectoryear percentile of the TFP distribution on the share of immigrants in the corresponding department, instrumented with the shift-share imputed percentage of immigrants (same explanatory variable and instrument used so far). One observation corresponds to one department-sector-year cell. Thus the estimated equations are the following:

$$
\left(n^{t h} T F P_{-} \text {percentile }\right)_{d, s, t}=\phi_{d}+\phi_{s}+\phi_{p}+\beta_{1}(\text { IMMIshare })_{d, t}+\varepsilon_{d, s, t}
$$

The dependent variable is in turn the value of $\ln \left(\right.$ TFP) at the $10^{t h}, 25^{t h}, 50^{t h}, 75^{t h}$ and $90^{\text {th }}$ percentile of the distribution across firms in the same department-sector-year. This regression identifies the effect of an increase of immigrants in the district at each percentile of the firm TFP distribution, not just at the average. Results for these estimates are reported in Table 11. Columns (1) and (2) present the OLS and the 2SLS estimation for different percentiles of the TFP distribution as dependent variable. In all specifications we include region and sector specific trend, while in columns 3 and 4 we also include department fixed effects. Both specification with and without department fixed effects show that the stronger positive effect of migration is on the less productive firms, with the coefficients decreasing in value up to the $90^{\text {th }}$ percentile.

Focusing on specifications including also department fixed effects, columns 3 and 4, we see that the immigrant share of employment had a positive effect on TFP at all the percentiles of the distribution. At the $50^{\text {th }}$ percentile the estimated effect is 0.5 , considering the $2 \mathrm{SLS}$ estimated. Interestingly we notice that the effects are not very different at the $75^{\text {th }}$ and $90^{\text {th }}$ percentile of the TFP distribution. However they are much larger (almost double) at the $10^{\text {th }}$ and $25^{\text {th }}$ percentile of the TFP distribution. In particular, according to 2 SLS estimations, an increase in the immigrant share by 10 percentage points of employment in a district would produce an increase by $5.0 \%$ of TFP for firms above the $50^{\text {th }}$ percentile of 
the TFP distribution, but as much as $7.6 \%$ for firms at the $10^{\text {th }}$ percentile. Less productive firms which are those with no immigrants initially, may take advantage from the availability of immigrants and potentially they can switch to cost-saving and more productive techniques. We think that this result is very interesting as firms initially not using immigrants and least productive are those ending up with the largest gains in productivity from immigration in the district. Along this dimension immigrants could contribute to reduce inequality.

\section{Conclusion}

This paper uses French firm level data to study the effect of immigration on a set of firms specific outcomes, related to the firms' productivity. A strong empirical regularity emerging from the analysis is that firms in district receiving a large inflow of immigrants experience productivity gains, faster investments, specialization of natives in complex occupations and faster export growth. Using enclave-driven instrument to proxy the supply-driven inflow of immigrants our analysis confirms that these effects are compatible with a causal interpretation. More interestingly, we find that firms initially not hiring immigrants are those that increase more their share of immigrants following an inflow in the district, when compared to other firms. Those are also the firms experiencing the largest productivity benefits, the largest growth in capital and in exports. We also find that wage and specialization effect of immigrants on natives are common within the labor market and not firm-specific. This evidence is compatible with a simple model in which firms have heterogeneous fixed costs of hiring immigrants and immigrants are complementary to natives. When their supply increases, some firms begin employing them in production, benefit from lower costs and move towards hiring the optimal share of immigrants which is higher the lower is their wage. As firms with initially no immigrants turn out to be among the less productive ones, immigration stimulated productivity growth for firms lagging behind. Hence it was particularly beneficial for under-performing firms. Immigration may induce some convergence in the productivity levels of firms that hire them, which is an aspect never considered or analyzed by the literature. 


\section{Bibliography}

Altonji, j. and D. Card, (1991) "The Effects of Immigration on the Labor Market Outcomes of Less-skilled Natives", NBER Chapters, in Immigration, Trade and the Labor Market, pp. 201-234.

Bernard, Andrew B. and Bradford Jensen, J., (1999). "Exceptional exporter performance: cause, effect, or both?," Journal of International Economics, Elsevier, vol. 47(1), pages 1-25, February.

Bernard Andrew B., Jonathan Eaton, J. Bradford Jensen and Samuel Kortum, (2003). "Plants and Productivity in International Trade," American Economic Review, American Economic Association, vol. 93(4), pages 1268-1290, September.

Borjas, G. (2003) "The Labor Demand Curve is Downward Sloping: Reexamining the impact of Immigration on the Labor Market", Quarterly Journal of Economics, 118(4): 1335-74.

Borjas, G. and L.F. Katz (2007) "The Evolution of the Mexican-Born Workforce in the United States", in Mexican Immigration to the United State, ed. G. Borjas, 13-56. University of Chicago Press.

Card, D. (2001) "Immigrants Inflows, Native Outflow, and the local Labor Market Impacts of higher immigration.", Journal of LAbor Economics, 19(1):22-64.

Card D. (2009) "Immigration and Inequality", American Economic Review, Papers and Proceedings, 99(2): 1-21. 
Chassamboulli, A. and T. Palivos (2013) "The impact of immigration on the employment and wages of native workers," Journal of Macroeconomics, vol. 38 , pages 19-34.

De New, J..P and K.F. Zimmermann (1994) "Native Wage Impacts of Foreign Labor: A Random Effects Panel Analysis" Journal of Population Economics, 7(2):177-92.

Dustmann, C., F. Fabbri and I. Preston (2005) "The Impact of Immigration on the British Labour Market" Economic Journal, 115(507): F324-F341.

Dustman, C., Frattinin, T. and I. Preston (2013) "The Effect of Immigration along the Distribution of Wages, Review of Economic Studies, 80(1), pp. 145-173.

Edo, A. (2013) "The Impact of Immigration on Native Wages and Employment", CES working paper 13-64.

Felbermayr, Gabriel, Grossmann, Volker and Kohler, Wilhelm, (2012). "Migration, International Trade and Capital Formation: Cause or Effect?," IZA Discussion Papers 6975, Institute for the Study of Labor (IZA).

Haas, A. and M. Lucht (2013) "Heterogeneous Firms and Imperfect Substitution: The Productivity Effect of Migrants" Norface Discussion Paper Series 2013019, Norface Research Programme on Migration, Department of Economics, University College London.

Hatzigeorgiou, A. and M. Lodefalk (2011) "Trade and Migration: Firm-Level Evidence", Working Papers 2011:6, Orebro University. 
Hiller, S. (2013) "Does immigrant employment matter for export sales? Evidence from Denmark", Review of World Economics, 149(2):369-394.

Hummels, D., R. Jorgensen, J.Munch and C. Xiang (2013) "The Wage Effects of Offshoring: Evidence from Danish Matched Worker-Firm Data", American Economic Review (forthcoming)

Kerr S.P. and W.R. Kerr (2011) "Economic Impacts of Immigration: A Survey" Finnish Economic Papers, vol. 24(1), pages 1-32.

Levinsohn, J. and A. Petrin (2003) "Estimating production functions using inputs to control for unobservables", Review of Economic Studies, 70(2):317-341.

Lewis, E. (2011) "Immigration, Skill Mix, and Capital Skill Complementarity", The Quarterly Journal of Economics, 126(2):1029-1069.

Lewis, E. (2013) "Immigration and Production Technology", Annual Review of Economics vol.5, Forthcoming, August 2013.

Longhi S., P. Nijkamp and J. Poot (2005) "A Meta-Analytic Assessment of the Effect of Immigration on Wages" Journal of Economic Surveys, vol. 19(3), pages 451-477, 07.

Malchow-Moller N., J.R. Munch and J.R. Skaksen (2012) "Do Immigrants Affect FirmSpecific Wages?" Scandinavian Journal of Economics, vol. 114(4):1267-1295.

Martins, P.S., Piracha, M. and J. Varejao (2012) "Do Immigrants Displace Native Workers? 
Evidence from Matched Panel Data" IZA Discussion Papers 6644, Institute for the Study of Labor (IZA).

Melitz, M. (2003) "The Impact of Trade on Intra-Industry Reallocations and Aggregate Industry Productivity" Econometrica, 71(6):1695-1725.

Olley, S.G. and A. Pakes (1996) "The dynamics of productivity in the telecommunications equipment industry", Econometrica, 64(6):1263-1297.

Ottaviano, G. and G. Peri (2012) "Rethinking the Effects of Immigration on Wages", Journal of the European Economic Association, 10(1):152-197.

Ottaviano, G., Peri, G. and G. Wright (2013) "Immigration, Offshoring and the American jobs", forthcoming American Economic Review.

Peri, G. (2012) "The Effect of Immigration on Productivity: Evidence from U.S. States" Review of Economics and Statistics, 94(1):348-358.

Peri, G. and C. Sparber (2009) "Task Specialization, Immigration, and Wages", American Economic Journal: Applied Economics, 1(3):135-69.

Peri, G. and F. Requena (2010) "The trade creation effect of immigrants: Testing the theory on the remarkable case of Spain", Canadian Journal of Economics, 49(4):1433-1459.

Trax M, S. Brunow and J. Sudekum (2013) "Cultural Diversity and Plant-Level Productivity" mimeo University of Duisenburg-Hessen. 
Van Beveren, I. (2012) "Total Factor Productivity Estimation: A Practical Review", Journal of Economic Surveys, 26(1):98-128. 


\section{Appendix A1: Sample description.}

A crucial issue to be clarified is the representativeness of the sample with respect to the initial data source. Our main dataset (containing info on the employment structure of French plants) is the DADS dataset, which is exhaustive and includes all the French establishments (plants) in the period 1995-2005. Notice that one firm may appear many times, depending on the number of establishments she holds and also on the sector where she operates. In the period 1995-2005, the DADS contains 13.922.675 observations (triplet plant-sector-year), among these 1.546 .871 observations belong to the Manufacturing sector, ${ }^{20} 12.344 .653$ to the service sector and the remaining to the primary sector. Because of data availability in balance sheet info, we focus on manufacturing sector only. Thus, when we collapse the 1.546 .871 manufacturing observations by counting only once all the multi-sector plants (establishments in more than one sub-sector of the industry sector) we end up with 1.534 .582 observations (plant-year).

Since the EAE dataset (containing balance sheet data) does not include the agro-industry sector, we have to exclude from the remaining DADS data also those plants belonging to the agro-industry sector. ${ }^{21}$ Then the number of plant-year observations reduces to 1.065.076.

After the merge between the DADS, Custom data and EAE datasets, we hold information for 218.895 plant-year in the manufacturing sector, ${ }^{22}$ which are those plants belonging to those firms having more than 20 employees (EAE provides info only for firms bigger than 20 employees). Finally the sample reduces to 160.367 observations if we include the TFP variable, which is available only over the period 1996-2005.

The huge drop in the number of plants (from original DADS to our final sample) is not surprising, because, by data availability constraint (EAE), we get rid of the many individual, micro and small enterprises in France. So it becomes important to clarify the representativeness of our final sample of firms in terms of the share over total employment in France

\footnotetext{
${ }^{20}$ According to the Naf 2-digit classification, the manufacturing sector includes activities from code 10 to 34

${ }^{21}$ Code 10 and code 11 according to the Naf 2 classification

${ }^{22}$ Activities from code 12 to 34 of the Naf 2 classification
} 
(or number of hours worked). In terms of employment (number of employees), our final dataset covers the $64 \%$ of the total French employment (in manufacturing sector in the period 1996-2005); while in terms of total hours worked our final sample represents the $66 \%$ of the total.

As a final step, since our main dependent variables (TFP, Capital and export variables) are at firm level, we need to collapse plant level information (SIRET id number) at firm level (SIREN id number). Then we end up with 136244 firm-year combinations.

\section{Appendix A2: Estimating TFP (total factor productivity)}

Let's define a Cobb-Douglas production function as follows:

$$
y_{j t}=\beta_{0}+\beta_{l} L_{i t}+\beta_{k} K_{i t}+\omega_{i t}+\epsilon_{i t}
$$

where $y_{i t}$ is the log of output (value added or revenue) of firm i at time $t$ (year in our data). We use value added to proxy output. As we do not observe physical output, we divide the value added by the Producer price index, 1995 prices at the NAF 2 digit level, and then we take the log (from Insee).

$L_{i t}$ and $K_{i t}$ are the log of inputs - labor and capital, respectively. The average number of employees during the year is used as a proxy for labour. For capital we used the value of tangible assets at the beginning of the period, deflated by the Real fixed capital stock, 1995 prices (from Euklems, http://www.euklems.net/).

$\omega_{i t}$ represents unobserved (for the econometrician) inputs that are known to the firm when it decides capital and labour. We refer to $\omega_{i t}$ as Total Factor Productivity (TFP). $\epsilon_{i t}$ is the error term. Now if $\omega_{i t}$ affects the choice of inputs, this leads to a simultaneity problem in the estimations of both $\beta_{l}$ and $\beta_{k}$, and thus a biased estimation of TFP.

To solve this problem, Olley and Pakes (1996) propose a semiparametric estimation method, derived from a theoretical model, showing the condition under which an investment proxy 
controls for correlation between input levels and the unobserved productivity shock. Olley and Pakes (1996) propose a firm-level competition model where firms have idiosyncratic efficiencies and face the same market structure and factor prices. Profits are a function of capital $K_{i t}$, efficiency $\omega_{i t}$, factor prices and other firms. $\omega_{i t}$ follows a first-order Markov process:

$$
\omega_{i t}=E\left[\omega_{i t} \mid \omega_{i(t-1)}\right]+\nu_{i t}=h\left(\omega_{i(t-1)}+\nu_{i t}\right)
$$

where $\nu_{i t}$ is uncorrelated with $K_{i t}$, but not necessarily with $L_{i t}$. The model compares for each firm, the value of continuing to produce with the value of liquidation. If firm continues in operation, chose labour and investment, knowing current efficiency $\omega_{i t}$ ). Investment choice at time $\mathrm{t}, l_{i t}$, gives the capital stock in the next period:

$$
K_{i(t+1)}=(1-\delta) K_{i t}+I_{i t}
$$

which means that time is needed to build physical capital. Investment is chosen at time $t$, but it is not productive until period $t+1$. The solution of the model generates two firm decision rules. First, the firm stops producing when its efficiency level falls below a given threshold (which increases monotonically with the capital stock). Second, if the firm does not exit, investment is a function of of current state variables.

$$
l_{i t}=I_{t}\left(K_{i t}, \omega_{i t}\right)
$$

Assuming monotonicity in the function $I_{t}($.$) we can invert and obtain the unobservable pro-$ ductivity as a function of two observed inputs, capital and investment:

$$
\omega_{i t}=g_{t}\left(l_{i t}, K_{i t}\right)
$$


We can re-express the the Cobb-Douglas production function in logs, in the value added case, as:

$$
y_{i t}=\beta_{l} L_{i t}+\phi_{i t}\left(K_{i t}, l_{i t}\right)+\epsilon_{i t}
$$

where

$$
\phi_{i t}\left(K_{i t}, l_{i t}\right)=\beta_{0}+\beta_{k} K_{i t}+g_{t}\left(l_{i t}, K_{i t}\right)
$$

and

$$
E\left(\epsilon_{i t} \mid L_{i t}, K_{i t}, l_{i t}\right)=0
$$

The first stage of the Olley and Pakes routine substitutes a third-order polynomial approximation in $k_{i t}$ and $i_{i t}$ in place of $\phi_{i t}$ and estimates $\beta_{l}$. In the second stage the coefficient $\beta_{k}$ is identified as follows. Estimated values for $\widehat{\phi}_{i t}$ are computed as

$$
\widehat{\phi}_{i t}=\widehat{y}_{i t}-\widehat{\beta}_{l} L_{i t}
$$

For a candidate value $\beta_{k}^{*}$ we obtain a prediction (upon a constant ) of $\widehat{\omega}_{i t}$ where

$$
\widehat{\omega}_{i t}=\widehat{\phi}_{i t}-\beta_{k}^{*} K_{i t}
$$

Assuming that productivity follows a first-order Markov process, $E\left[\omega_{i t} \mid \omega_{i(t-1)}\right]$ is given by predicted values from regression:

$$
\widehat{\omega}_{i t}=\gamma_{0}+\gamma_{1} \widehat{\omega}_{i(t-1)}+\gamma_{2} \widehat{\omega}_{i(t-2)}^{2}+\gamma_{3} \widehat{\omega}_{i(t-3)}^{3}+\epsilon_{i t}
$$

to which we can refer to $\widehat{E}\left[\omega_{i t} \mid \omega_{i(t-1)}\right]$. The estimate of $\beta_{k}$ is defined as a solution to the minimization of:

$$
\min _{\beta_{k}^{*}} \sum\left(y_{i t}-\widehat{\beta}_{l} L_{i t}-\beta_{k}^{*} K_{i t}-\widehat{E}\left[\omega_{i t} \mid \omega_{i(t-1)}\right]\right)^{2}
$$


Finally using $\widehat{\beta}_{l}$ and $\widehat{\beta}$, TFP is estimated as a residual of the Cobb-Douglas production function. Levinsohn and Petrin (2003) have extended the Olley and Pakes (1996) approach to contexts where data on capital investment presents significant censoring at zero investment. They propose a two-stage estimation, using intermediate materials as a proxy for the unobserved productivity shock. In the paper we have approssimated intermediate inputs by the cost of materials, deflated by the Intermediate inputs price index, 1995 prices (from Euklems). Intermediate inputs $m_{i t}$ are expressed as a function of capital stock $K_{i t}$ and productivity $\omega_{i t}$

$$
m_{i t}=m_{t}\left(K_{i t}, \omega_{i t}\right)
$$

Assuming monotonicity in the function $m_{t}($.$) we can invert and obtain the unobservable$ productivity as a function of two observed inputs, capital and intermediates:

$$
\omega_{i t}=g_{t}\left(m_{i t}, K_{i t}\right)
$$

The LP routine is then processed in the same way than the OP routine,described above. All in all Levinsohn and Petrin (2003) allow to retain more observations than the Olley and Pakes (1996) estimation, because typically firms report a positive use of inputs, and as a consequence, the monotonicity condition is more likely to hold for intermediates than for investments.

\section{Appendix A3: Complexity measures by occupation}

In order to measure the complexity of tasks covered by native workers, we computed indices of communication, cognitive and manual complexity for each of the occupations covered by native workers among French firms. To this end, we use the 2010 version of O*NET dataset which includes measures of the importance, on a scale from 0 to 100 , of more than 200 worker and occupational characteristics (e.g. finger dexterity, oral expression, thinking 
creatively, operating machines) in about 974 tasks, based on the six-digit Standard Occupational Classification (SOC) classification. We follow Peri and Sparber (2009), and we focus on the dichotomy communication versus manual tasks, as our index of how complex a task is. For the definition of manual skills we average 19 O*NET variables capturing an occupation "Movement and strength" requirements. For the communication intensity index we average 4 O*NET variables considering oral and written expression and comprehension (see Table A7). The complexity index by occupation is simply the measure of the Communication intensity of the occupation itself or its ratio over the manual complexity.

As an alternative indicator to proxy tasks-complexity we also use the dichotomy cognitive versus manual tasks. For the cognitive task we use 10 O*NET variables, as in Table A7. Once we have calculated our complexity measure by task, we construct the measure of complexity of occupations at the firm level using the DADS dataset. Unfortunately the two data sources are not directly comparable; some concordance problems exist. While O*NET data set uses six- SOC codes, in the DADS the variable occupation follows the four-digit Professions et Categories Socioprofessionnelles des Emplois Salaries d'entreprise (PCS-ESE) nomenclature. Matching the two datasets requires putting both of them in a common nomenclature, that is the 1988 International Standard Classification of Occupations (ISCO -88). This causes other concordance issues. Firstly, correspondence tables exist only between the six-digit SOC 2007 and 4-digit ISCO-88 and between the four-digit PCS-ESE 2003 and the three-digit ISCO -88. Secondly, the PCS-ESE nomenclature has been revised twice during the period 1982-2007. These two points imply harmonizing all the PCS-ESE codes within the DADS dataset, reporting all them at the four-digit PCS-ESE 2003 version. Moreover when attributing at each four-digit PCS-ESE 2003 code a "Complexity index"we reduce the information originally contained in the O*NET database. We are obliged to compute an average of the "Complexity index"at the three-digit ISCO-88 occupation codes, which means having a "Complexity index" for 130 PCS-ESE codes compared to the 414 original ones. 


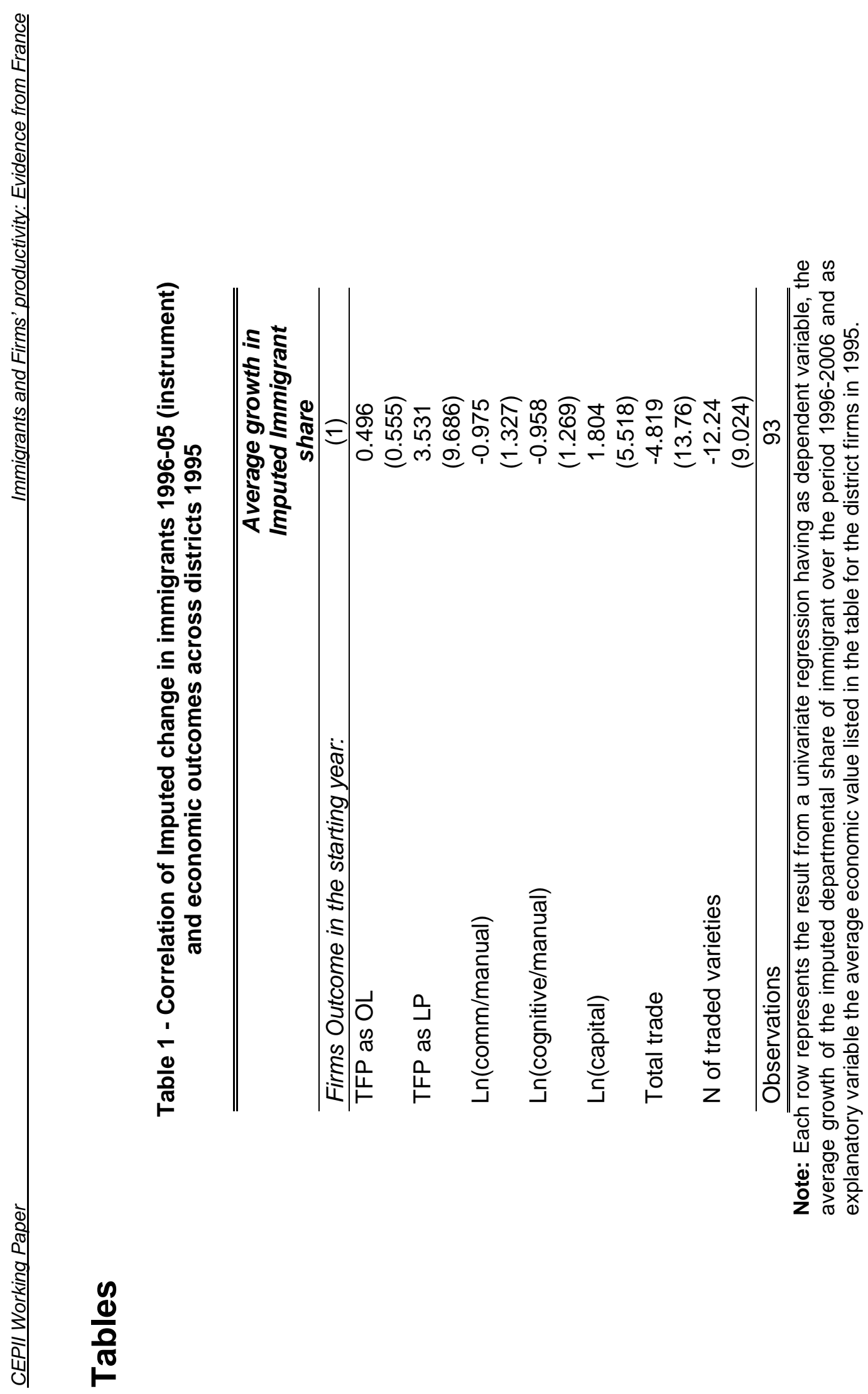




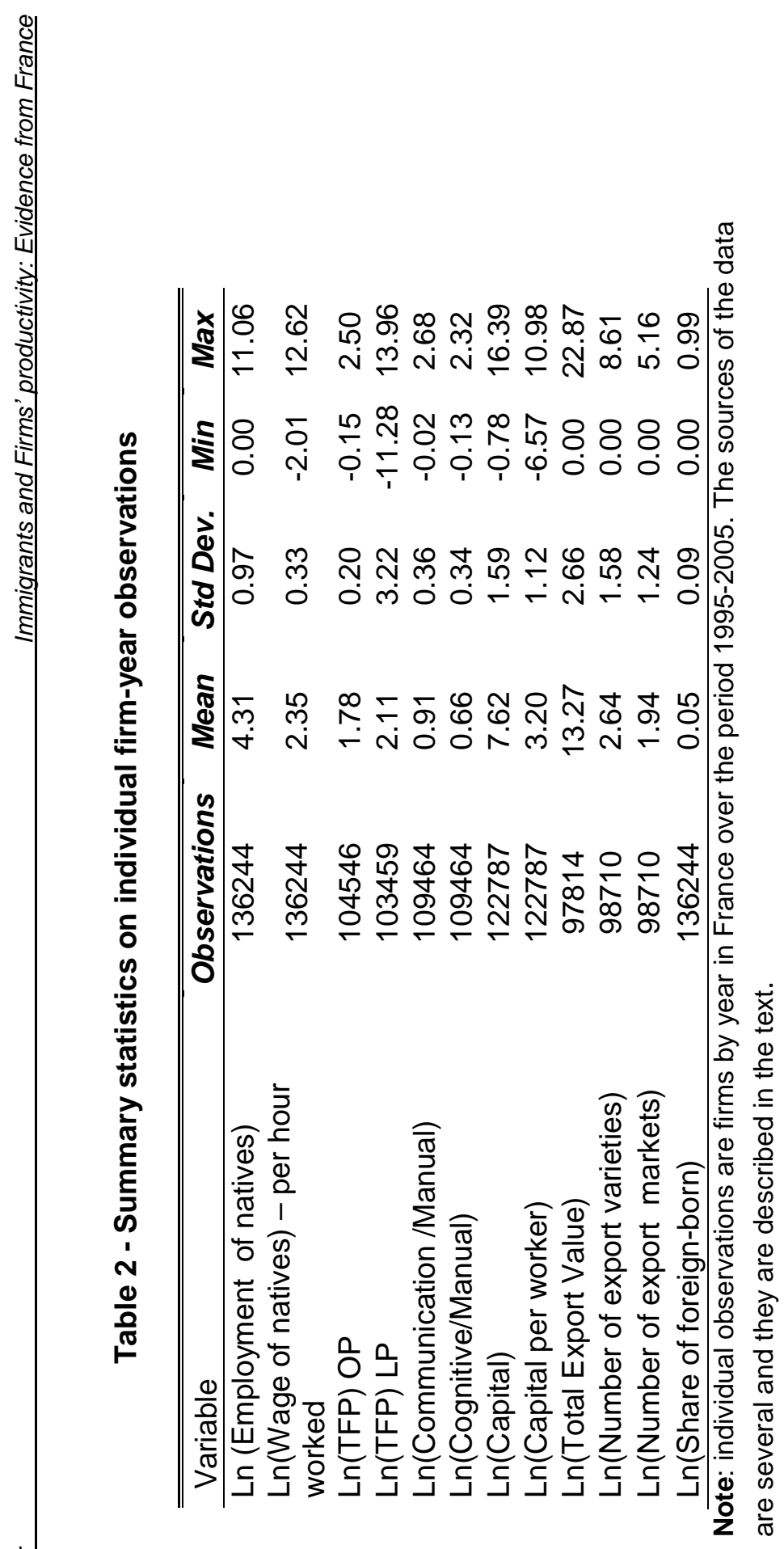




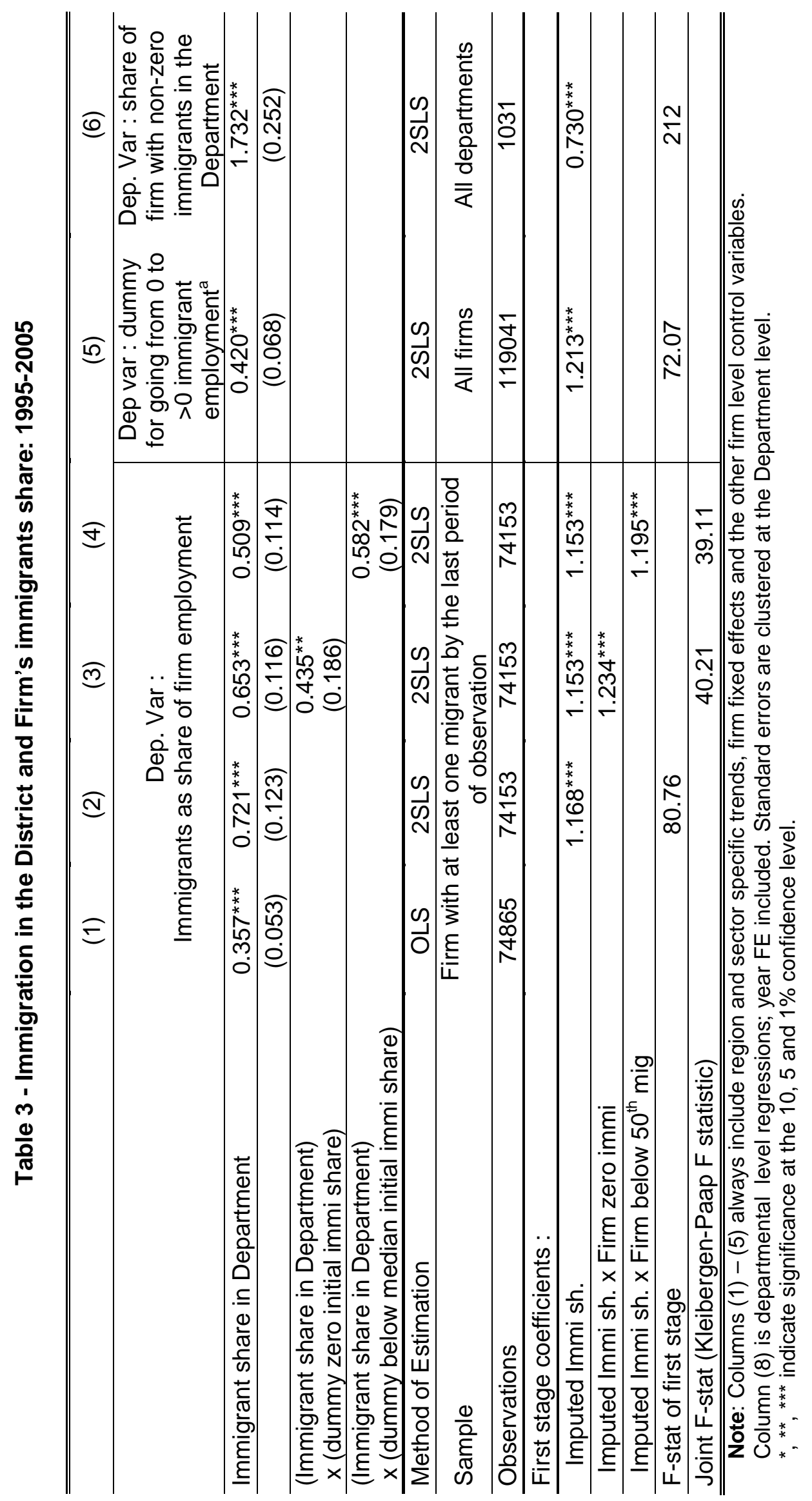


|

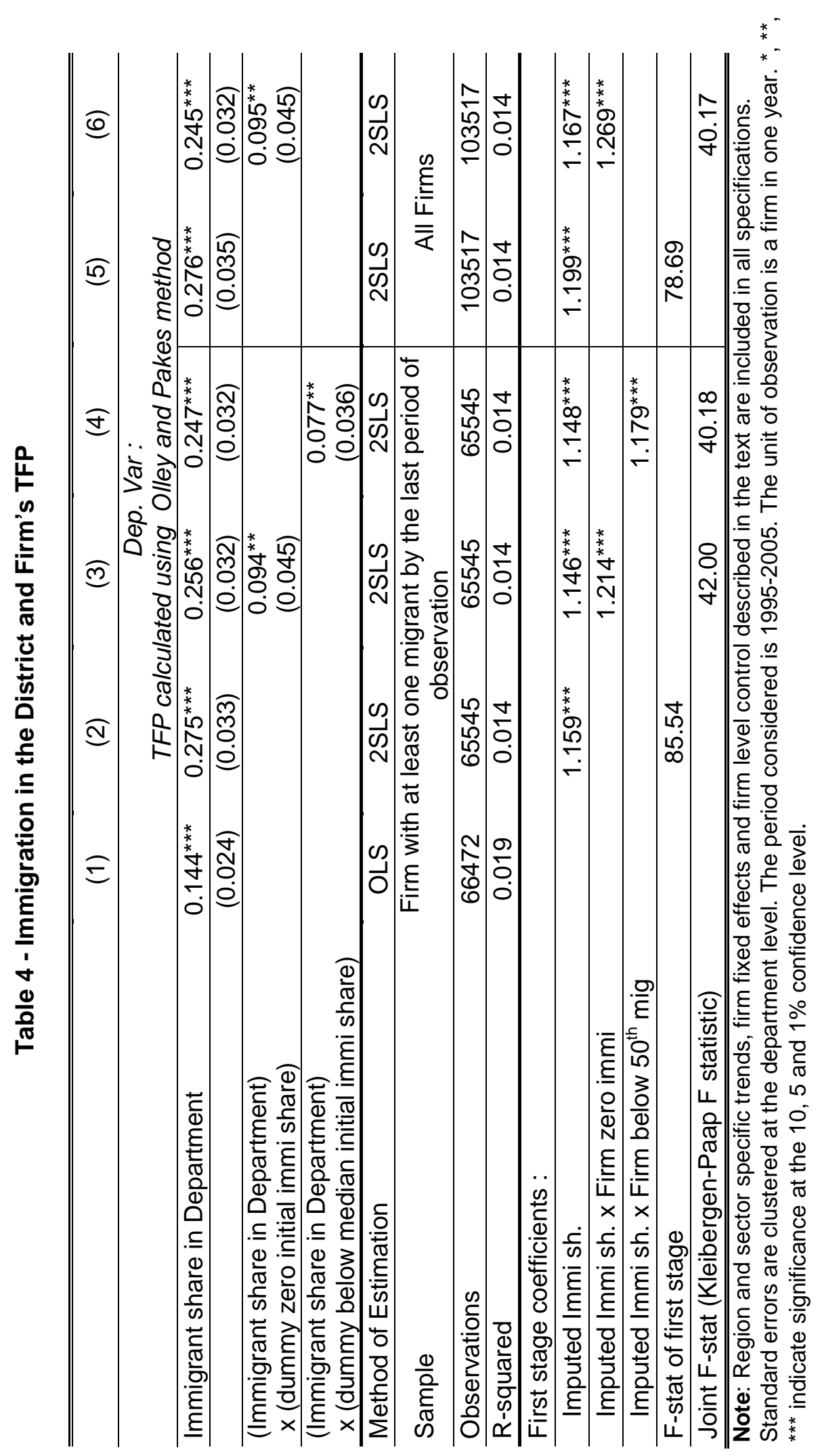


|

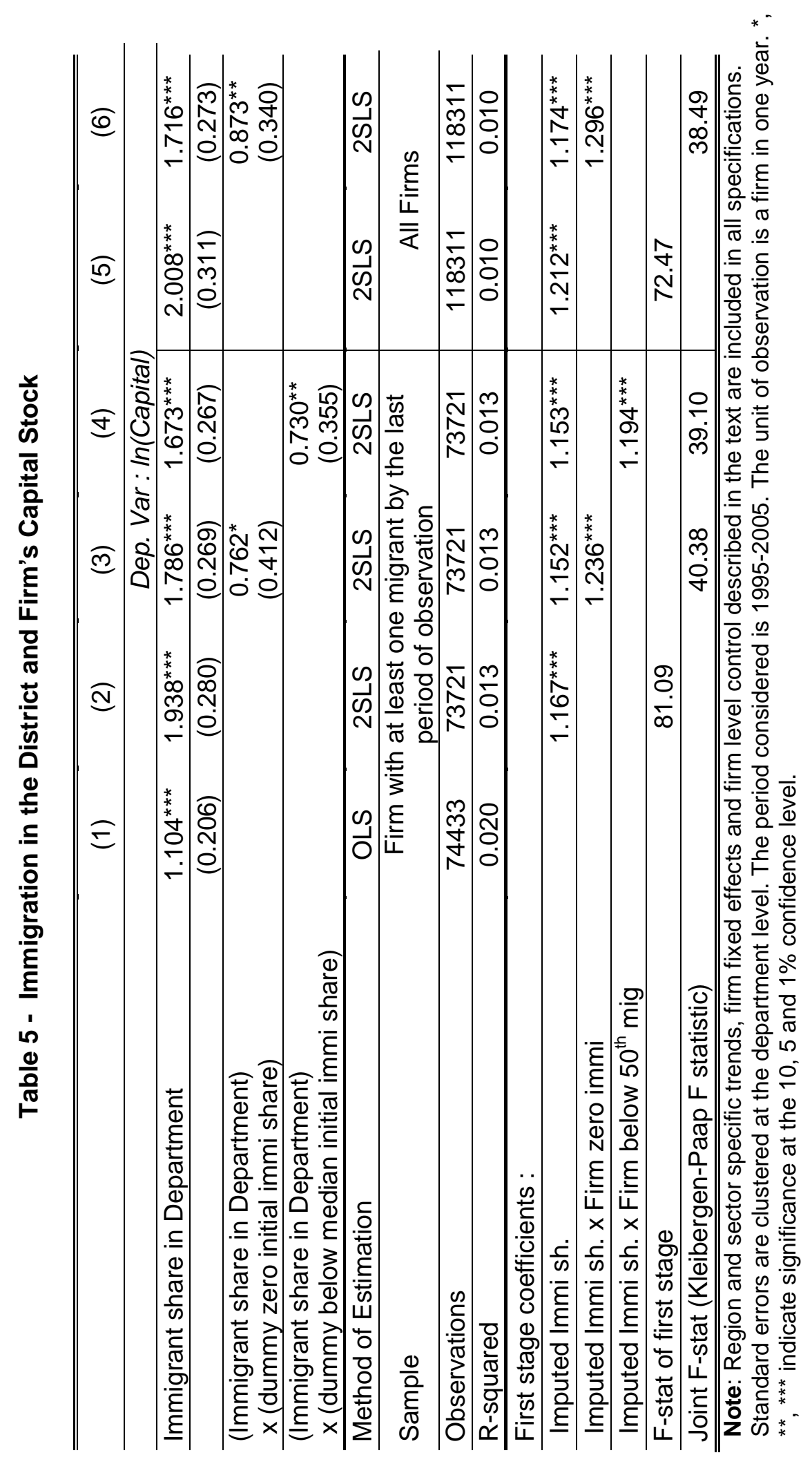


|

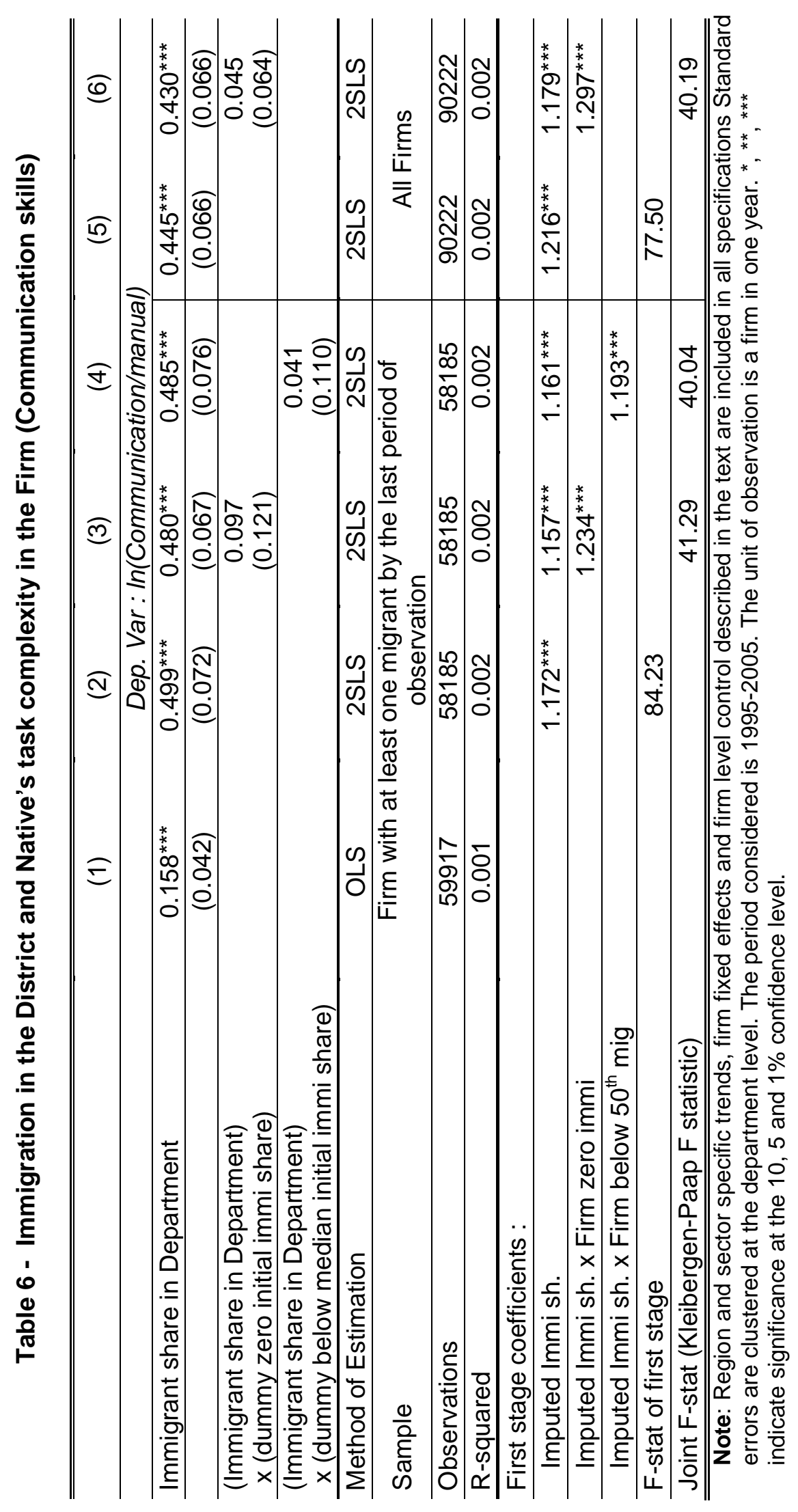


है

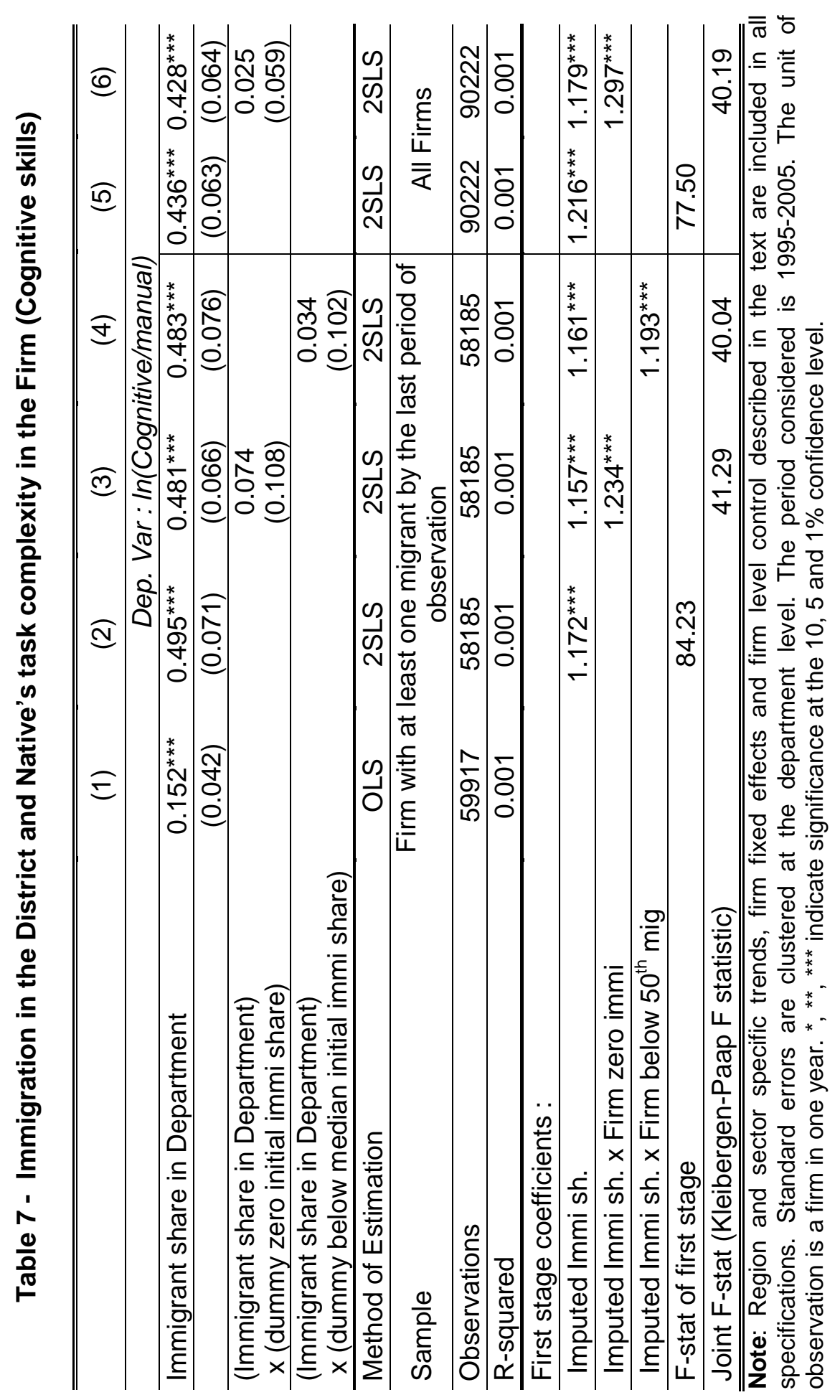




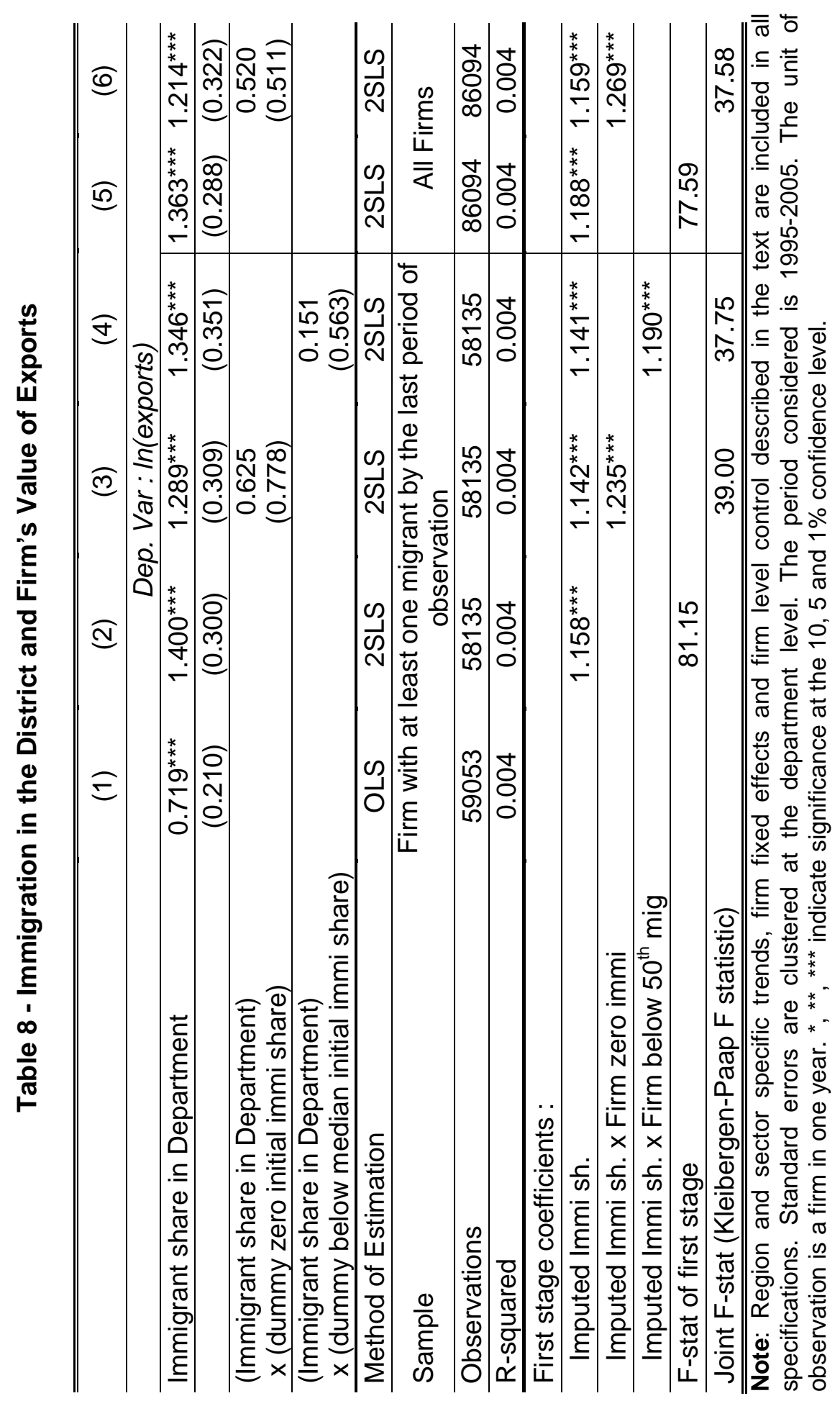




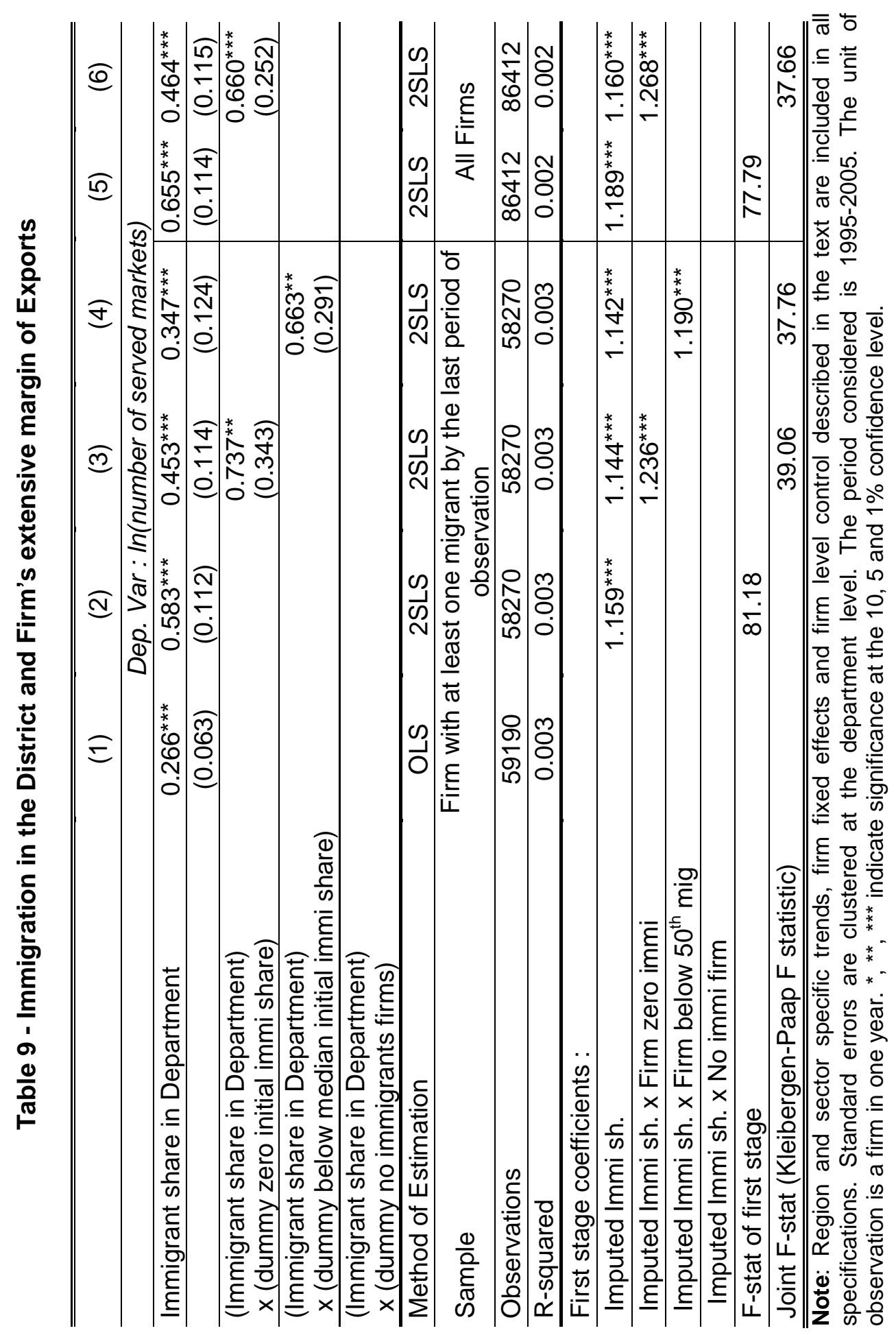




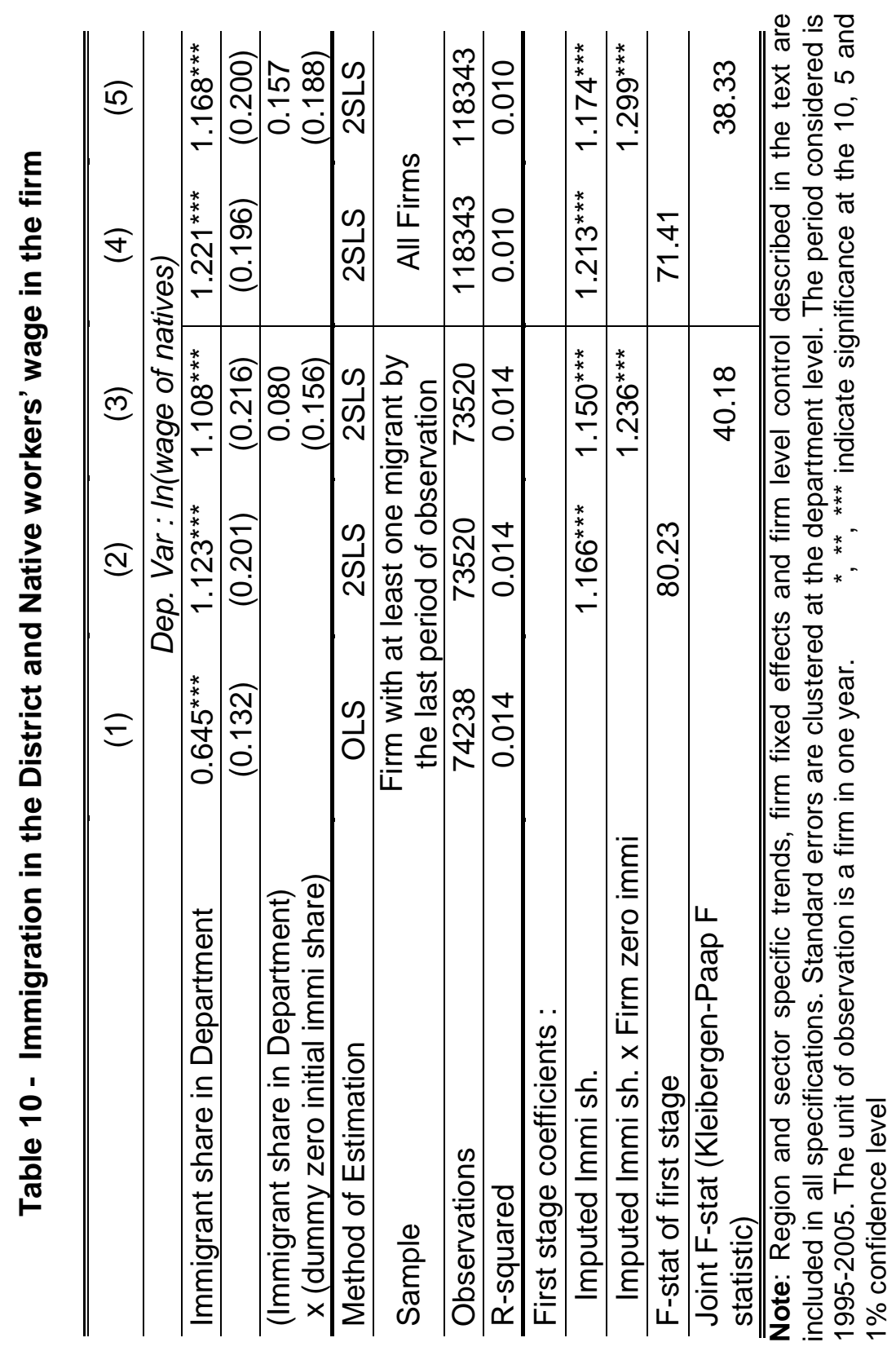




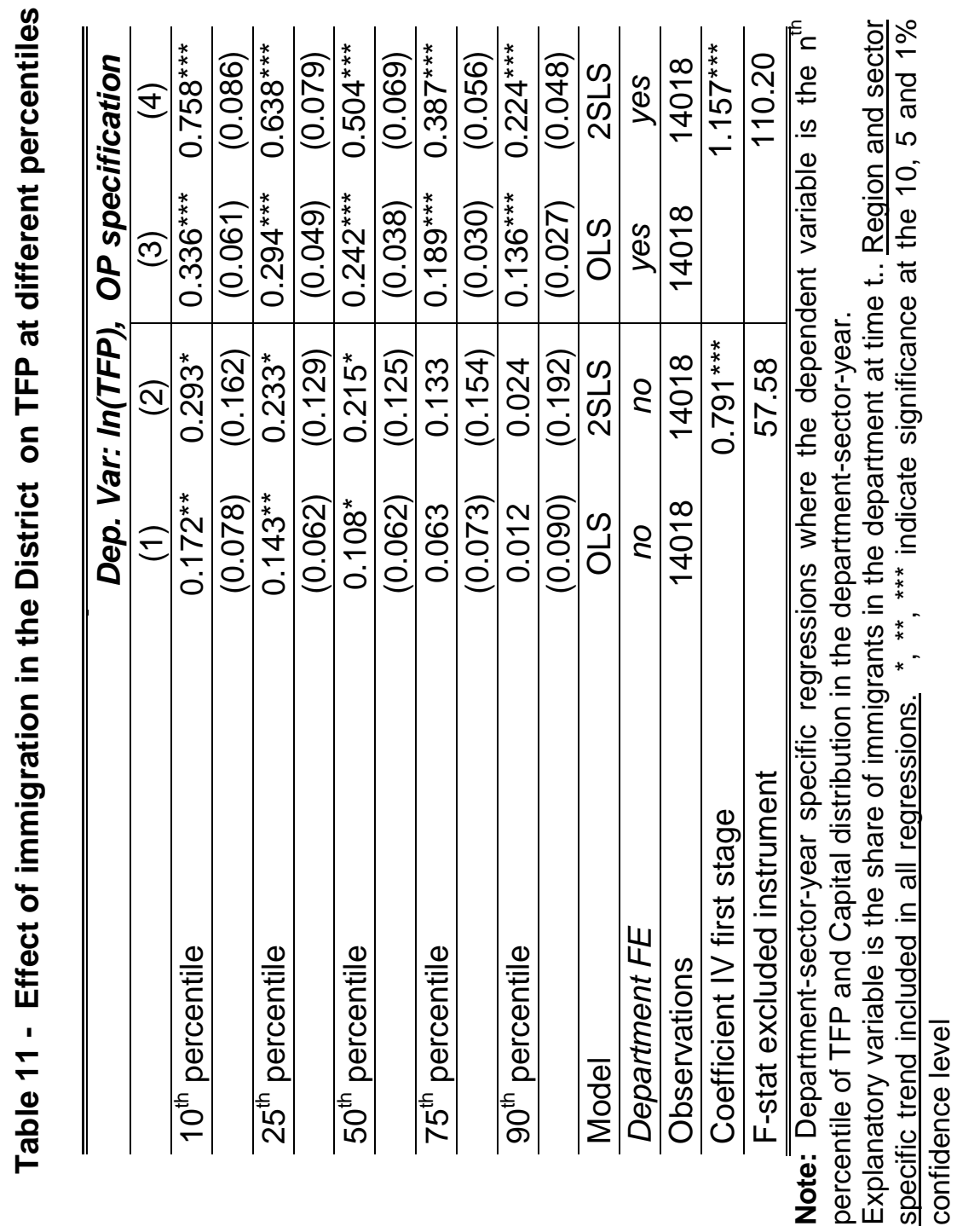



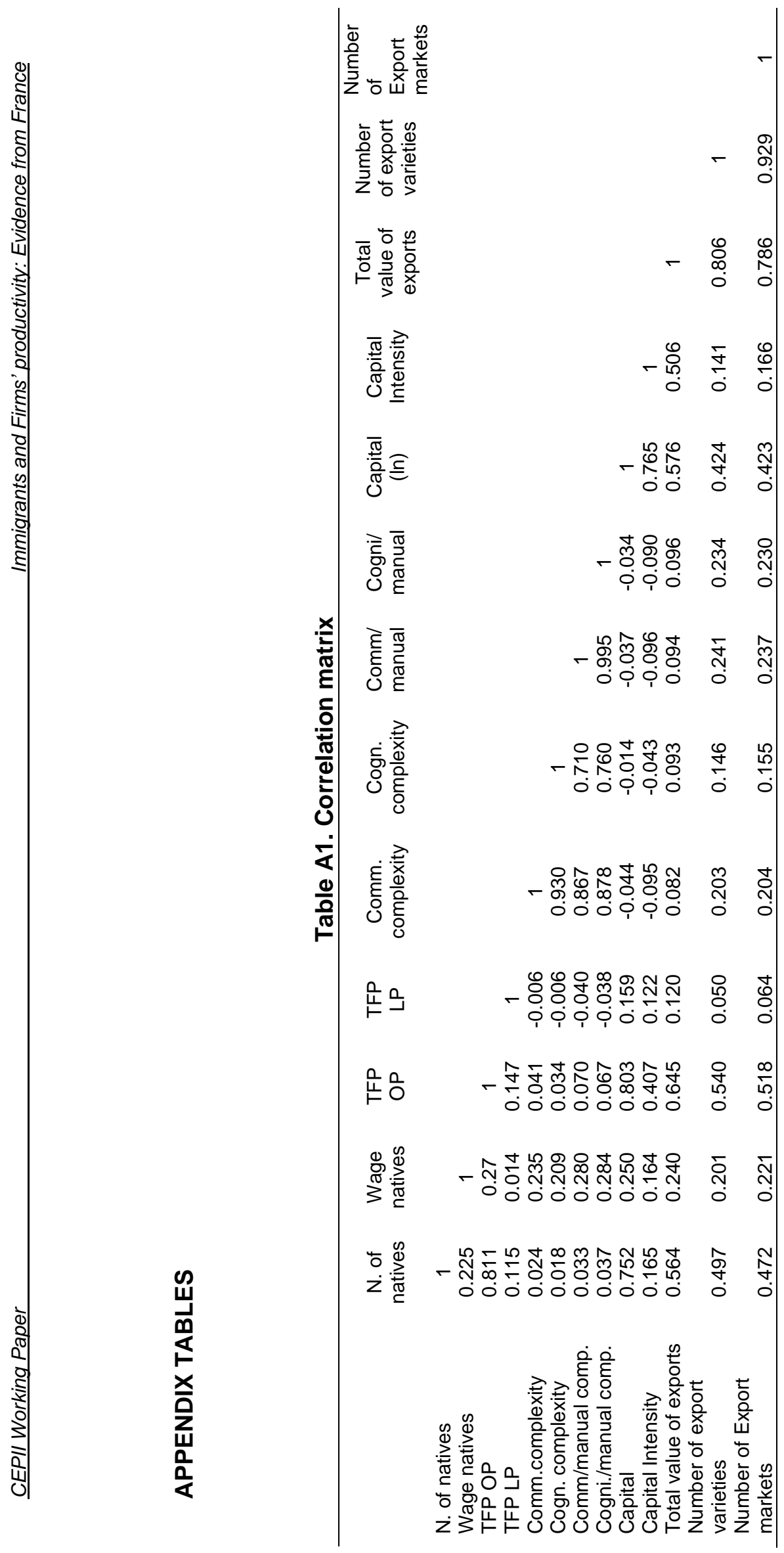


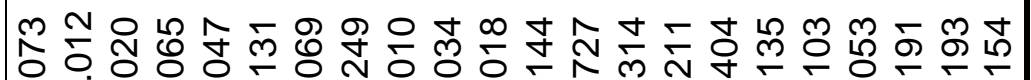

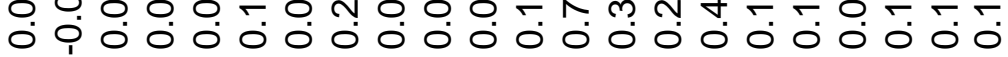

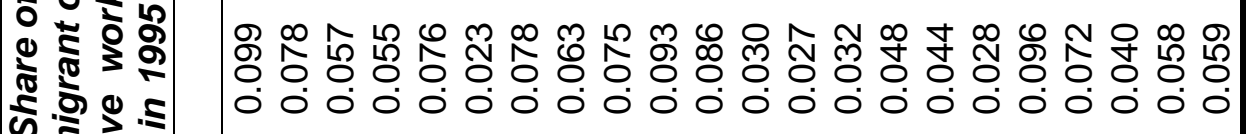

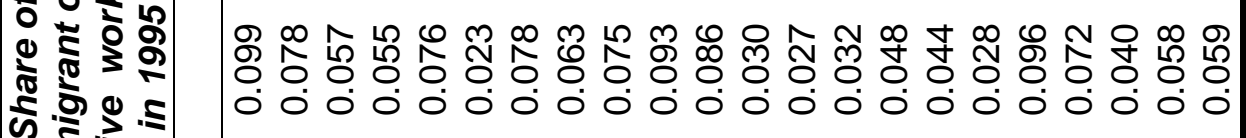

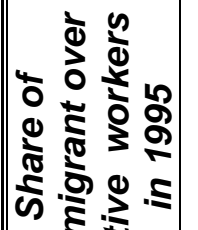
$\Sigma=\frac{1}{2}$ ริ 은 
|

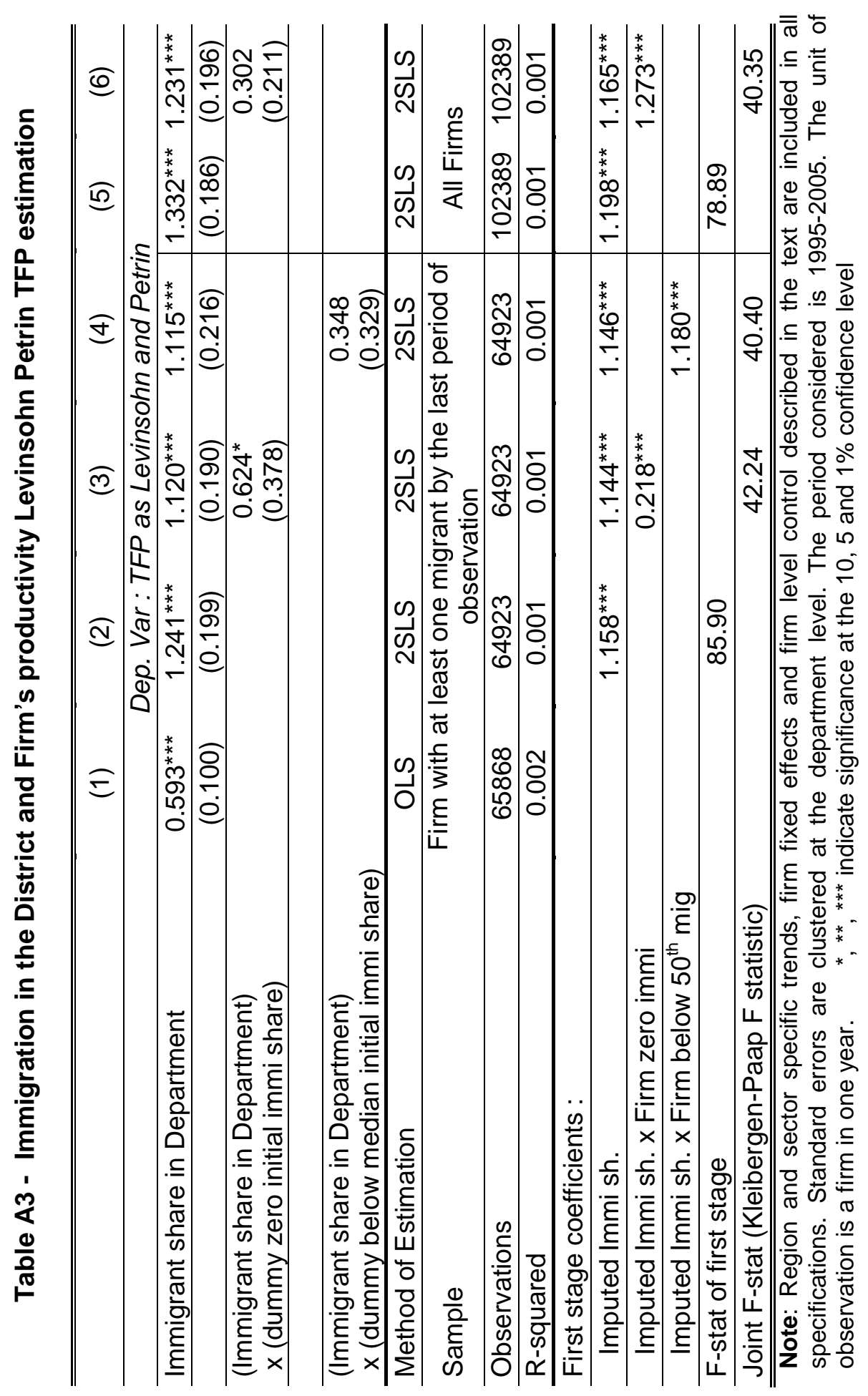




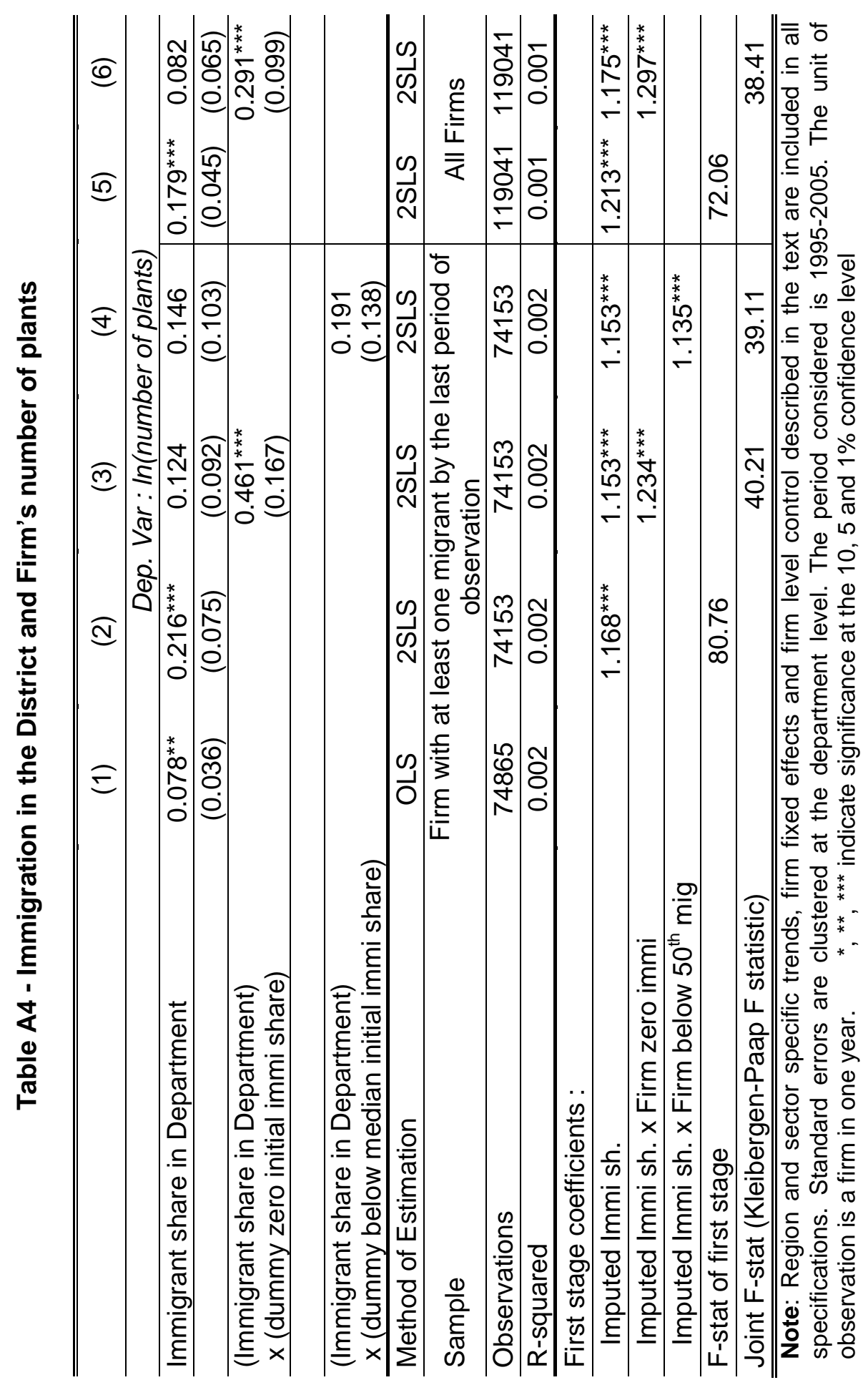




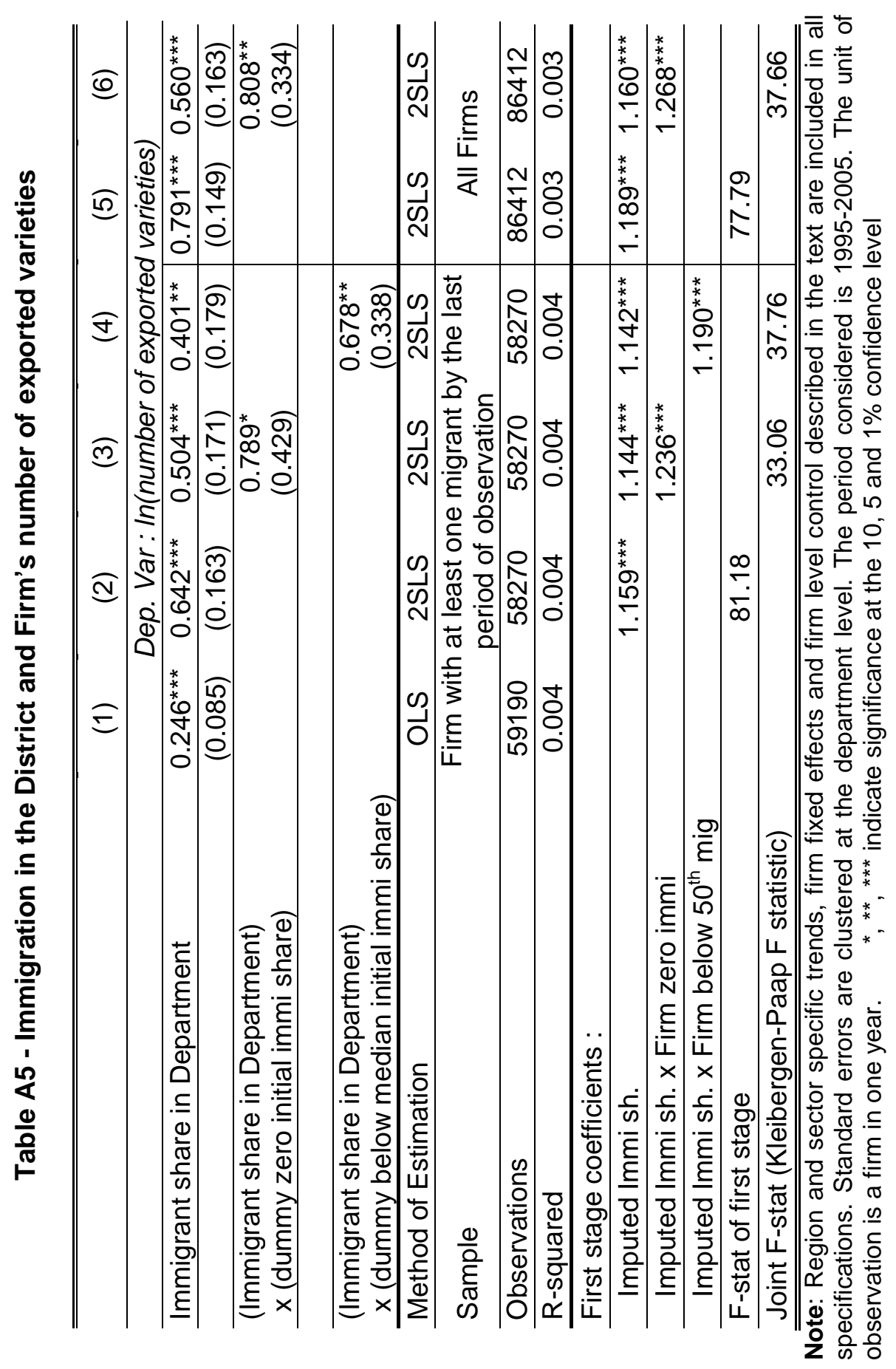




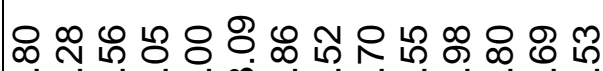

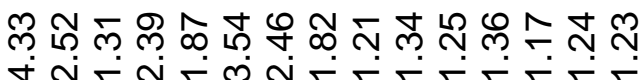
- mó丶万ர்

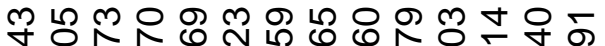
-

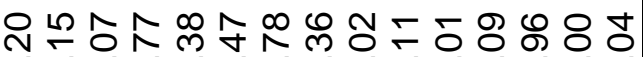
m

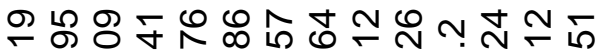
ช่ำกำกำ

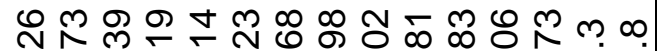

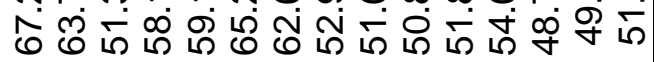

๓

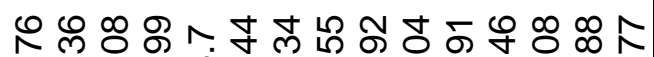

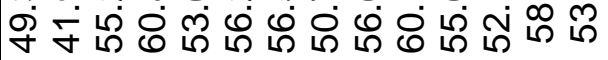
守

$\sum_{\frac{\pi}{2}}^{\frac{\pi}{2}}$

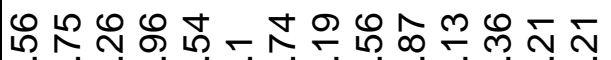
लं

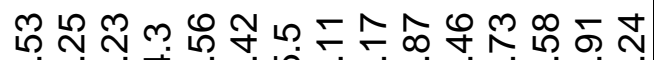

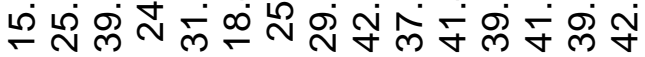

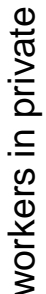

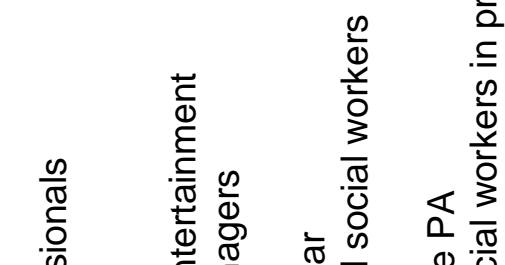

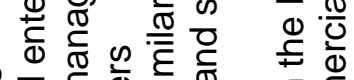

क ัँ

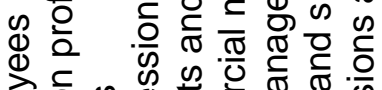

की

.

क षे

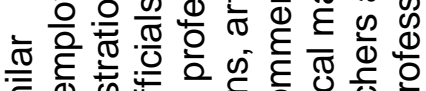

ㅎํ응

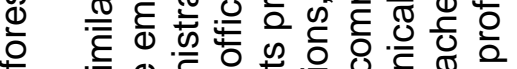

ত্் $\frac{\omega}{\omega}$ क

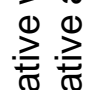

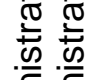

亏ั

言

흥

ర్ల

을

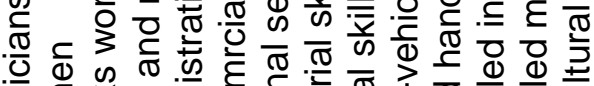
ర은

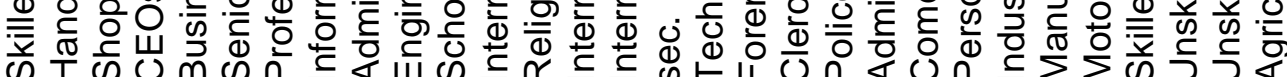

U 


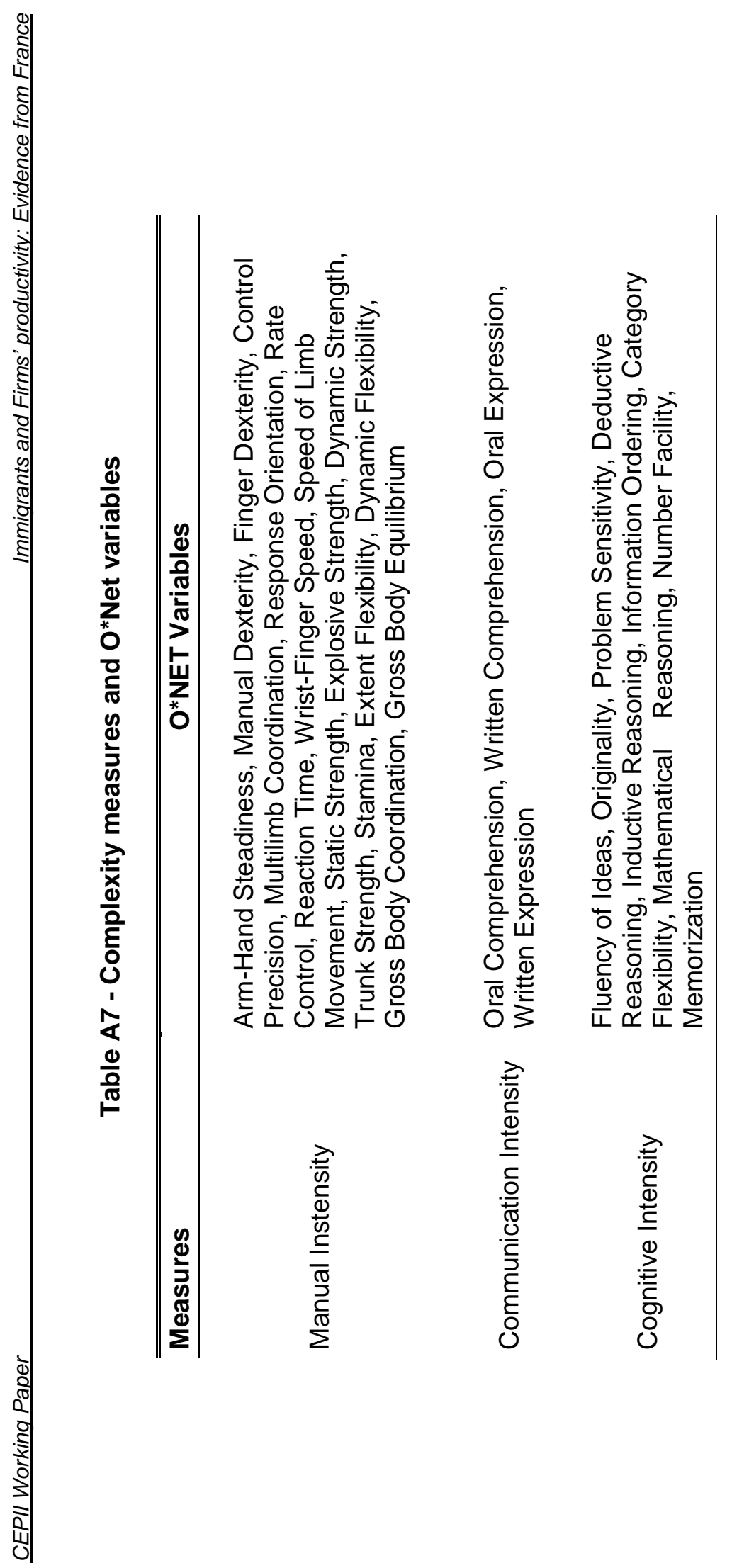


Table A8 - Correlation between the share of immigrants across French departments in 1995 and 2005

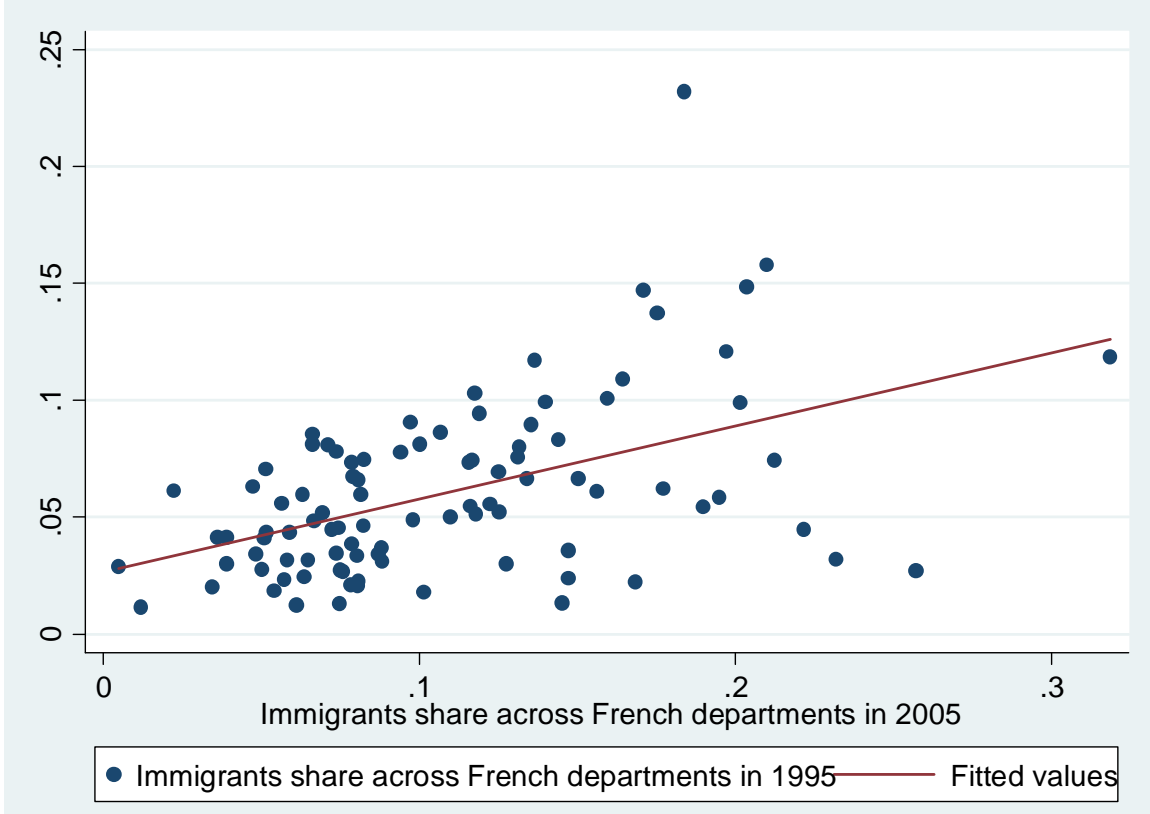

Table A9 - Changes in immigrant employment across French firms (2005-1996)

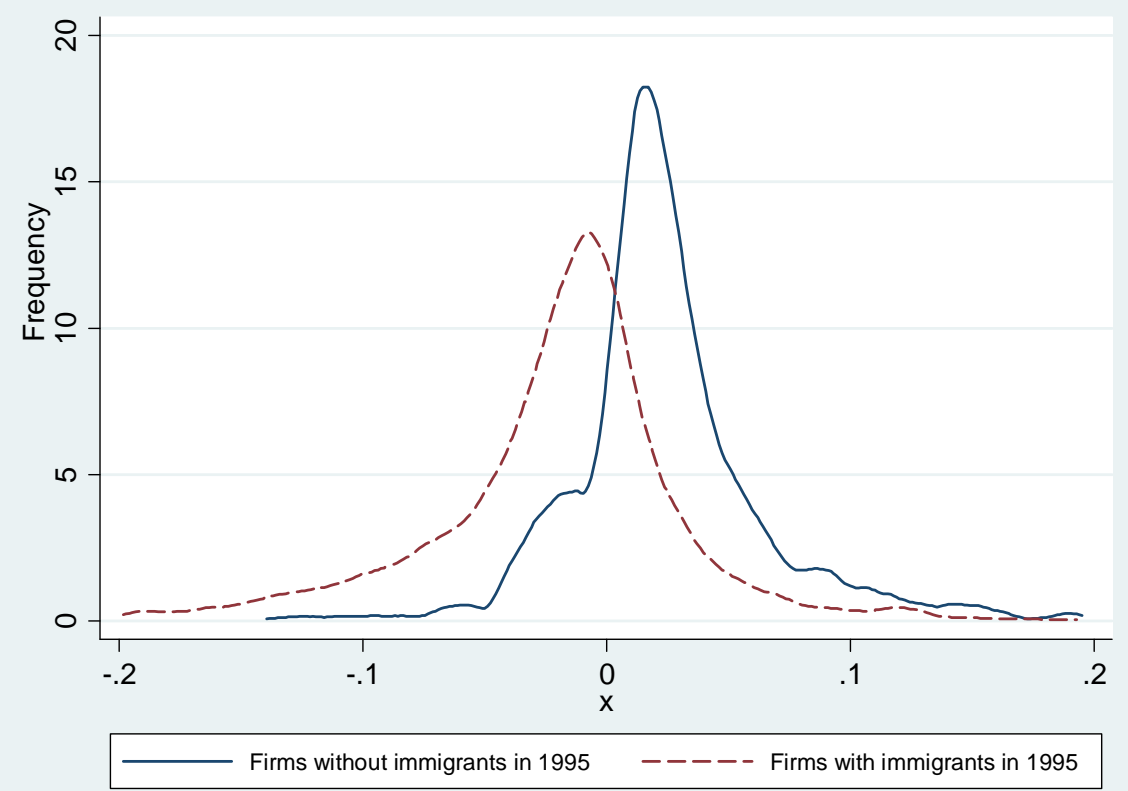

NOTE: Firms experienced no differences in their share of immigrants have been dropped here. 
Table A10 - Changes in TFP levels across French firms (2005-1996)

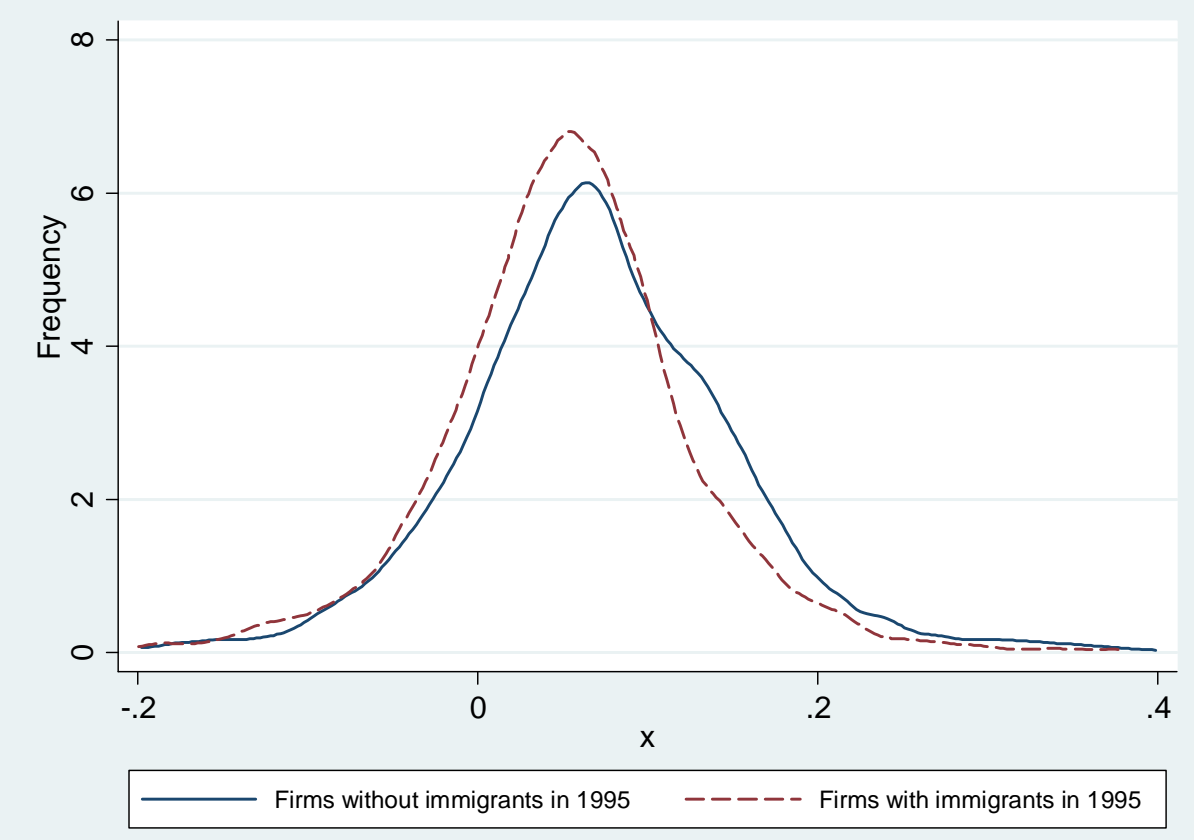

